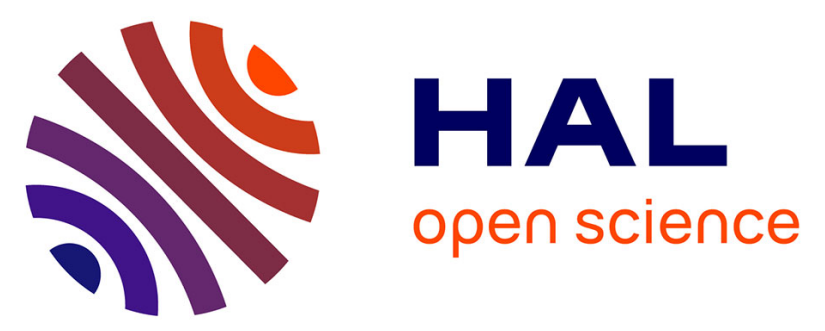

\title{
Science objectives and performances of NOMAD, a spectrometer suite for the ExoMars TGO mission
}

Ann Carine Vandaele, Eddy Neefs, Rachel Drummond, Ian R. Thomas, Frank

Daerden, Jose Lopez-Moreno, J. Rodriguez, Manish R. Patel, D. Bellucci, M.

Allen, et al.

\section{To cite this version:}

Ann Carine Vandaele, Eddy Neefs, Rachel Drummond, Ian R. Thomas, Frank Daerden, et al.. Science objectives and performances of NOMAD, a spectrometer suite for the ExoMars TGO mission. Planetary and Space Science, 2015, 119, pp.233-249. 10.1016/j.pss.2015.10.003 . insu-01216807

\section{HAL Id: insu-01216807 https://hal-insu.archives-ouvertes.fr/insu-01216807}

Submitted on 15 Jan 2022

HAL is a multi-disciplinary open access archive for the deposit and dissemination of scientific research documents, whether they are published or not. The documents may come from teaching and research institutions in France or abroad, or from public or private research centers.
L'archive ouverte pluridisciplinaire HAL, est destinée au dépôt et à la diffusion de documents scientifiques de niveau recherche, publiés ou non, émanant des établissements d'enseignement et de recherche français ou étrangers, des laboratoires publics ou privés.

\section{(1) (1) $\$$}

Distributed under a Creative Commons Attribution - NonCommercial - NoDerivatives 44.0 


\title{
Science objectives and performances of NOMAD, a spectrometer suite for the ExoMars TGO mission
}

\author{
A.C. Vandaele ${ }^{\text {a,* }}$, E. Neefs ${ }^{a}$, R. Drummond ${ }^{\text {a }}$, I.R. Thomas ${ }^{\text {a }, ~ F . ~ D a e r d e n ~}{ }^{\text {a }}$, J.-J. Lopez-Moreno b \\ J. Rodriguez ${ }^{\mathrm{b}}$, M.R. Patel ${ }^{\mathrm{c}, \mathrm{q}}$, G. Bellucci ${ }^{\mathrm{d}}$, M. Allen $^{\mathrm{e}}$, F. Altieri $^{\mathrm{d}}$, D. Bolsée ${ }^{\mathrm{a}}$, T. Clancy $^{\mathrm{f}}$, \\ S. Delanoye ${ }^{a}$, C. Depiesse ${ }^{a}$, E. Cloutis ${ }^{g}$, A. Fedorova ${ }^{\text {h }}$, V. Formisano ${ }^{d}$, B. Funke ${ }^{b}$, D. Fussen a \\ A. Geminale ${ }^{\text {d }}$, J.-C. Gérard ${ }^{i}$, M. Giuranna ${ }^{d}$, N. Ignatiev ${ }^{\text {h }}$, J. Kaminski ${ }^{j}$, O. Karatekin ${ }^{k}$, \\ F. Lefèvre ${ }^{1}$, M. López-Puertas ${ }^{b}$, M. López-Valverde ${ }^{b}$, A. Mahieux ${ }^{a}$, J. McConnell ${ }^{j}$, \\ M. Mumma ${ }^{\mathrm{m}}$, L. Neary ${ }^{\mathrm{a}}$, E. Renotte ${ }^{\mathrm{n}}$, B. Ristic ${ }^{\mathrm{a}}$, S. Robert ${ }^{\mathrm{a}}$, M. Smith ${ }^{\mathrm{m}}$, S. Trokhimovsky \\ h J. Vander Auwera ${ }^{\circ}$, G. Villanueva ${ }^{p}$, J. Whiteway ${ }^{j}$, V. Wilquet ${ }^{a}$, M. Wolff ${ }^{\text {, }}$, \\ The NOMAD Team
}

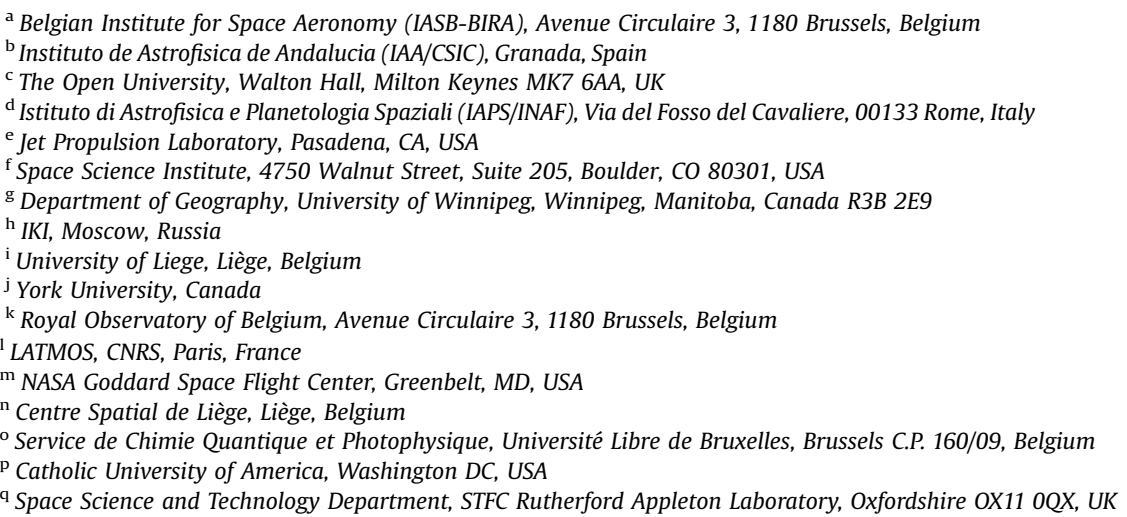

\section{ABSTRACT}

The NOMAD spectrometer suite on the ExoMars Trace Gas Orbiter will map the composition and dis-tribution of Mars' atmospheric trace species in unprecedented detail, fulfilling many of the scientific objectives of the joint ESA-Roscosmos ExoMars Trace Gas Orbiter mission. The instrument is a combination of three channels, covering a spectral range from the UV to the IR, and can perform solar occultation, nadir and limb observations. In this paper, we present the science objectives of the instrument and how these objectives have influenced the design of the channels. We also discuss the expected performance of the instrument in terms of coverage and detection sensitivity.

\footnotetext{
* Corresponding author.

E-mail address: a-c.vandaele@aeronomie.be (A.C. Vandaele).
} 


\section{Introduction}

Disequilibria in the chemical composition of Mars can be attributed to processes related to geophysical activity (e.g. volcanism, outgassing, water-rock interactions), exogenous input (e.g. comets and meteorites), or biological activity, i.e. originating from extinct or extant life. The presence of reduced gases such as methane $\left(\mathrm{CH}_{4}\right)$ in an oxidizing atmosphere could be indirect evidence of life (Allen et al., 2006; Hitchcock and Lovelock, 1967; Yung et al., 2010). Until recently however, spectroscopic compo-sition analysis of the Martian atmosphere showed no signs of trace gas disequilibria (see Krasnopolsky (2010) for an overview). But a decade ago, several potential detections of $\mathrm{CH}_{4}$ were reported both from Earth (Krasnopolsky et al., 2004; Mumma et al., 2009b) and from Mars orbit (Fonti and Marzo, 2010; Formisano et al., 2004), which implied recent replenishment of methane. Methane on Mars can be of either geophysical, exogenous or biological origin (Krasnopolsky, 2006a; Sherwood Lollar et al., 2006). Pinpointing the exact origin requires measurements of methane isotopologues and of other trace gases related to possible methane production/ sequestration processes, such as serpentinization (Atreya et al., 2007) or release of methane from clathrates (Chassefière, 2009). Observational evidence that the methane destruction occurs on timescales orders of magnitude shorter than its expected lifetime, has not yet been fully understood (Lefevre and Forget, 2009; Mumma et al., 2009a; Zahnle et al., 2011). Positive Earth-based observations of methane (above a detection limit of $\sim 7 \mathrm{ppb}$ ) were not repeated since 2006 (Villanueva et al., 2013) while the Planetary Fourier Spectrometer (PFS) (Formisano et al., 2005) continued to measure methane (Geminale et al., 2008, 2011) from orbit.

In 2011, the Mars Science Laboratory (MSL) (Grotzinger et al., 2012) was launched by NASA. The rover, called Curiosity, landed into the Gale crater and has recently revealed some contradictory results. Its main scientific objectives are to search for traces of a possible favourable environment (past or present) for the appearance of life. One of the instruments on board Curiosity is dedicated to the detection of carbon, oxygen, hydrogen and nitrogen, and is sensitive to methane, i.e. the Tunable Laser Spectrometer (TLS), which belongs to the SAM (Sample Analysis of Mars, Mahaffy et al. (2012)) suite. The first observation reported by the SAM team (Webster et al., 2013) was a non-detection of methane. The measured concentration indicated a mean value of $0.18 \pm 0.67 \mathrm{ppbv}$, too low to claim detection. However the reported upper limit of 1.3 ppbv was significantly lower than the previous observations. Since then Curiosity has performed new observations using in particular the 'methane enrichment' methodology. The latest results show a highly variable local methane concentration, with back-ground values of methane of $0.69 \pm 0.25 \mathrm{ppbv}$ and elevated levels of $7.19 \pm 2.06 \mathrm{ppbv}$ (Webster et al., 2015).

Follow-up and further refinement of the existing methane measurements with additional measurements of a broader suite of related trace species, both in column and profile at a global scale, will be crucial to better understand the presence or absence of biological processes, as well as the current level of geophysical activity on Mars. Atmospheric markers of other geophysical activity such as volcanism and outgassing $\left(\mathrm{SO}_{2}\right.$ and $\mathrm{H}_{2} \mathrm{~S}$ ) have so far not been detected (Khayat et al., 2015; Krasnopolsky, 2005; Villanueva et al., 2013). Predicted abundances for gases related to such activity are very low (Wong et al., 2003). A survey at high spectral and spatial resolution from Mars orbit may detect locally enhanced levels e.g. at active vents not detectable by earlier surveys.

NOMAD, the "Nadir and Occultation for MArs Discovery" spectrometer suite, was selected as part of the payload of the ExoMars Trace Gas Orbiter mission 2016. The instrument will conduct a spectroscopic survey of Mars' atmosphere in UV, visible and IR wavelengths covering large parts of the $0.2-4.3 \mu \mathrm{m}$ spectral range. NOMAD is composed of 3 channels: a solar occultation only channel (SO - Solar Occultation) operating in the infrared (2.3-4.3 $\mu \mathrm{m})$, a second infrared channel $(2.3-3.8 \mu \mathrm{m})$ capable of doing nadir, but also solar occultation and limb observations (LNO -Limb Nadir and solar Occultation), and an ultraviolet/visible channel (UVIS UV visible, $200-650 \mathrm{~nm}$ ) that can work in all observation modes. The spectral resolution of SO and LNO sur-passes previous surveys from orbit in the infrared by more than one order of magnitude. NOMAD offers an integrated instrument combination of a flightproven concept - SO is a copy of SOIR-Solar Occultation in the IR (Nevejans et al., 2006) on Venus Express (VEx) (Titov et al., 2006), and innovations based on existing and proven instrumentation LNO is based on SOIR on Venus Express and UVIS has heritage from the ExoMars lander, that will provide mapping and vertical profile information at high spatio-temporal resolution.

\section{Scientific objectives}

\subsection{The ExoMars mission}

The ExoMars (Exobiology on Mars) is the first mission in the Exploration program of the European Space Agency (ESA) in collaboration with the Russian Space Agency (Roscosmos), with the aim to search for signs of life, past or present on Mars. It will also serve to demonstrate qualification of flight and in situ technologies necessary for future exploration missions. Its technical objectives are to demonstrate: (1) the safe entry, descent and landing of a large size payload (Descent Module); and (2) the surface mobility and access to the subsurface (Rover). The mission includes several spacecraft elements to be sent to Mars on two launches. The ExoMars Trace Gas Orbiter (TGO) and an Entry and Descent Demonstrator (EDM) lander called 'Schiaparelli' are planned for launch in 2016. In 2018, a Roscosmos-built lander will deliver the ESA-rover to the Martian surface. The TGO orbiter of the first mission element (2016) will carry four scientific instruments and will also serve as communication relay satellite for the NASA rovers already on the surface of Mars and for the future ExoMars rover delivered in 2018. The timeline of the 2016 mission is based on a launch in January 2016 and arrival at Mars in October the same year. After EDM separation, the spacecraft enters an aero-braking phase that will end in November 2017, when the Science Phase starts. The nominal Science Phase will end in November 2019, although the spacecraft will continue acting as a relay until the end of 2022. Science will be possible during that period but it will have a lower priority.

The scientific objectives of the payload on board the Trace Gas Orbiter (TGO) and on the 2018 surface platform and rover are:

1. To search for signs of past or present life on Mars.

2. To investigate how the water and geochemical environment varies, i.e. by characterizing their distributions in the atmosphere, on and near the surface or as a function of depth in the shallow subsurface.

3. To investigate Martian atmospheric trace gases and their sources.

4. To study the surface environment and identify hazards to future manned missions to Mars.

5. To investigate the planet subsurface and deep interior to better understand the evolution and habitability of Mars.

Moreover, ExoMars is considered to be the first step towards a sample return mission. 
2.2.1.3. $\mathrm{CH}_{4}$ chemistry and related geophysical/biogenic activity. NOMAD will contribute to solving the current question on the existence and persistence of Martian methane by providing unequivocal measurements of this trace gas: its presence, variability, and the processes related to its origin and destruction, and by potential discrimination of geophysical versus biogenic origin. NOMAD will survey atmospheric methane and its isotopologues through vertical profiling and horizontal mapping of total and fractional columns. Simultaneous detection of $\mathrm{CH}_{4}$ and higher hydrocarbons such as $\mathrm{C}_{2} \mathrm{H}_{6}$ will help to assess the origin of $\mathrm{CH}_{4}$. The photochemical depletion of $\mathrm{C}_{2} \mathrm{H}_{6}$ with respect to $\mathrm{CH}_{4}$ is about 25 (Krasnopolsky, 2006b), so that if the source of $\mathrm{CH}_{4}$ were abio-genic the same ratio should be observed in their respective abundance (Onstott et al., 2006). Comparison of the isotopic ratios, in particular $\delta^{13} \mathrm{C}$ of $\mathrm{C}_{2} \mathrm{H}_{6}$ with that of $\mathrm{CH}_{4}$ could distinguish abiogenic $\mathrm{CH}_{4}$ from thermogenic or biogenic sources (Allen et al., 2006; Onstott et al., 2006). NOMAD will also measure gases related to serpentinization $\left(\mathrm{C}_{2} \mathrm{H}_{2}\right.$ and $\left.\mathrm{C}_{2} \mathrm{H}_{4}\right)$ and species related to clathrates $\left(\mathrm{H}_{2} \mathrm{O}\right.$ and $\mathrm{CH}_{4}$, combined with observations of dust, ice deposits and temperature profiles). In addition, NOMAD provides high sensitivity to formaldehyde $\left(\mathrm{H}_{2} \mathrm{CO}\right)$ which is a photochemical product of methane, as well as $\mathrm{N}_{2} \mathrm{O}$ and $\mathrm{H}_{2} \mathrm{~S}$ which are potential atmospheric biomarkers.

2.2.1.4. Volcanism. The main cluster of volcanoes and lavas lies in Tharsis, another smaller one in Elysium. Based upon images from the ConTeXt camera on Mars Reconnaissance Orbiter (Robbins et al., 2011), the activity in Tharsis has been estimated to have ended around $150 \mathrm{Myr}$ ago. However, although recent active volcanism on Mars has not been observed, the presence of active outgassing vents may still be possible (Langevin et al., 2005; Neukum et al., 2004). Major gas releases associated with volcanic outgassing are expected to be sulphuric, i.e. $\mathrm{SO}_{2}$ and $\mathrm{H}_{2} \mathrm{~S}$. The relative proportions between the sulphur bearing species are indications to the conditions of their formation, but also of processes taking place after release, such as photochemistry (Wong et al., 2003, 2004a, 2005).

2.2.1.5. Upper atmosphere climatologies. The upper atmosphere is the least described region of the Martian atmosphere, and is of paramount importance for aerobraking manoeuvres and escape processes. NOMAD is particularly suited to measure the low densities and temperatures of the upper tenuous atmosphere of Mars. Solar occultation has proven to be the most accurate strategy to sound thermospheric altitudes, in the case of Venus (Mahieux et al., 2010, 2012, 2015a, 2015b; Vandaele et al., 2008). Also the NOMAD limb emission capabilities can be exploited at high alti-tudes improving the solar fluorescence of molecules like $\mathrm{CO}_{2}$ and $\mathrm{CO}$. Non-LTE models will be used to exploit such data, including absorption in hot bands and rotational non-LTE. Energy balance in the IR, from $\mathrm{CO}_{2}$ non-LTE emissions will be validated and used to improve GCM at high altitudes.

\subsubsection{Mars climatology and seasonal cycles}

Prior missions such as Viking, Mars Global Surveyor (MGS), Mars Odyssey (MOD), Mars Express (MEx), Mars Reconnaissance Orbiter (MRO) and Phoenix, have characterized the seasonal and global variations (climatology) of the current Martian atmosphere. Distinct and generally repeatable patterns occur in pressure, carbon dioxide deposition, temperature, aerosol (dust and water ice cloud) optical depth, and gas abundance, but there are also significant interannual variations. Continued observations are needed to better quantify the interannual variability and understand the physical mechanisms that govern the current climate. The most striking interannual variation is associated with global dust storms, which occur roughly every three Martian years (MY). Many aspects of the aerosol climatology are not yet well characterized, such as local time variation, the vertical distribution of aerosols and water vapour, and wind velocities. An example of a refinement in the water cycle was provided by the Phoenix mission, which contributed to the understanding of the condensation of water vapour to the surface throughout the polar summer and fall season (Daerden et al., 2010; Whiteway et al., 2009). The seasonal variation of non-condensable gases such as $\mathrm{CO}, \mathrm{O}_{3}$, and $\mathrm{CH}_{4}$ are also important (Lefevre and Forget, 2009; Smith, 2009). Characterization of their seasonal and spatial variations will constrain atmospheric dynamics and the timescales for mixing in the atmosphere. In general, these gases are not yet well characterized. CRISM/MRO provided a CO climatology (Smith et al., 2009a), but with no vertical information.

The SPICAM/MEx climatology of total ozone columns (Perrier et al., 2006) confirmed the standard photochemical picture of the Martian atmosphere (Lefevre et al., 2004). Still the widely varying conditions over latitudes, local times and seasons present challenges to our understanding of the finer-scale processes governing the ozone photochemistry (Krasnopolsky, 2010; Lefevre et al., 2008; Montmessin and Lefèvre, 2013) and require a continued and refined survey of ozone, both in total column and vertical profile. This will also allow derivation of a surface UV climatology, which is relevant for assessing the habitability conditions at the Martian surface and for future Mars exploration.

2.2.2.1. Extend existing atmospheric climatologies. NOMAD will extend the existing atmospheric climatologies for $\mathrm{CO}_{2}, \mathrm{CO}, \mathrm{H}_{2} \mathrm{O}$ and other trace species, but also for temperatures and total densities. The retrieval of temperature, of pressure and of total density have been proven from the spectra obtained by SOIR/VEx (Mahieux et al., 2010, 2012, 2015a). The same approach will lead to similar measurements of the Martian atmosphere. Several aspects of the existing climatologies are not yet well characterized, such as local time variation, the vertical distribution of aerosols and water vapour.

2.2.2.2. Improve $\mathrm{UV}$ and $\mathrm{O}_{3}$ climatology. The UVIS channel (200-650 $\mathrm{nm}$ ) will provide measurements of $\mathrm{O}_{3}$ in solar occultation (vertical profiles) and nadir (total columns). An improved $\mathrm{O}_{3}$ cli-matology will advance our understanding of photochemical pro-cesses in the Martian atmosphere, through the use of radiative transfer modelling of the atmosphere. These measurements should also solve the discrepancy between the SPICAM O ${ }_{3}$ values (Perrier et al., 2006) and values obtained by Earth ground-based instruments (Krasnopolsky, 2009) or by photochemical models of the Mars atmosphere (Krasnopolsky, 2010; Lefevre et al., 2008), and will also to investigate if heterogeneous chemistry processes are playing an important role on Mars (Lefevre et al., 2008).

2.2.2.3. Dust and clouds climatology. While vertically extended dust aerosols are present in the atmosphere of Mars throughout the year, atmospheric dust lifting and column loadings vary strongly in location, season, and Mars Year (e.g., Cantor et al., 2001; Smith, 2004). Generally northern spring and summer exhibit minimum conditions of dust loading compared to northern autumn and winter, when peak global surface and atmospheric heating is associated with Mars perihelion. In this perihelion season dust storms of different sizes and duration interact to produce regional and/or planet encircling major dust events (Cantor, 2007). Such perihelic dust storms are characterized by high altitudes of dust lifting (e.g., Clancy et al., 2010) and strong interannual variability in seasonal timing and global extent (Smith, 2009). Evidence of global vertically stratified dust distributions in northern summer as well as regional dust layering over volcano topography indicates the importance of locally forced dust 
injection on dust vertical distributions (Daerden et al., 2015; Heavens et al., 2015). Recently, Montabone et al. (2015) have updated the known climatology of dust using multiple datasets of retrieved or estimated column optical depth for the Martian years 24-31. The datasets are based on observations of the Martian atmosphere from March 1999 to July 2013 by different orbiting instruments.

The water cycle is closely coupled to the dust cycle in several ways. Dust aerosols absorb solar flux and so heat the atmosphere and impact water vapour saturation conditions. Conversely, background levels of fine dust aerosols serve as condensation nuclei for ice cloud formation. The distribution of dust therefore highly influences the location and also the microphysical properties of the clouds. Conversely, the dust cycle is influenced by sedimentation and sublimation of the cloud particles This interplay between dust and ice aerosols and the vertical distribution of water vapour couples with the global Hadley circulation to create significant seasonal forcing of the global water cycle (Clancy et al., 1996). Dust particles both absorb and scatter light, primarily absorbing in the visible and radiating in the infrared, and so influencing the thermal and dynamical state of the atmosphere as well as surface temperatures (e.g., Gierasch and Goody, 1972). The infrared radiative properties of clouds also play an important role in the radiative equilibrium of the Martian atmosphere and surface (e.g., Wilson et al., 2008). Slant aerosol optical depths are derived routinely from solar occultation observations, from which vertical profiles can be derived, as has been demonstrated with SOIR/VEx (Wilquet et al., 2009, 2012). Measurement of the aerosol opacity across a wide wavelength range (i.e. UV to IR) also allows the optical properties and size distribution of the suspended aerosols to be derived through modelling of the phase function (Wilquet et al., 2009). The presence of ice (both $\mathrm{H}_{2} \mathrm{O}$ and $\mathrm{CO}_{2}$ ) clouds will be measurable through wavelength-dependent scattering in the observed UV and IR spectra.

The knowledge of aerosol optical depth is important for accurate retrieval of gas abundances under nadir viewing, as it tends to "fill in" - reduce the apparent strength of - the spectral features. Over dark surface regions (e.g. Acidalia, Syrtis Major), dust aerosols can also produce a noticeable brightening that can in principle be used to estimate their optical depth. However, over bright regions (e.g. Arabia, Tharsis) this effect is not significant and so it is difficult to estimate dust optical depth from nadir visible/near IR observations in general (Mateshvili et al., 2007). On the other hand, ice clouds and their optical depths can be quantitatively determined from nadir blue and ultraviolet observations, due to their high single scattering albedo (1.0) and very low albedos for all non-ice surface regions (Mateshvili et al., 2009; Wolff et al., 2010).

\subsubsection{Sources and sinks of the Martian atmosphere}

The inventory of trace gases and the characterization of their spatio-temporal distribution and variability will provide a global picture of the composition of the Martian atmosphere. While the major climatologic patterns are now well understood, more work is required to refine the various components which play a role in the seasonal cycles. An example of such a refinement is, for the water cycle, the precipitation of large ice crystals as detected by Phoenix (Daerden et al., 2010; Whiteway et al., 2009). For methane, the variability detected by MSL (Webster et al., 2015) requires substantial further investigation in order to understand the processes observed. To improve our understanding of the processes controlling these trace gases, correlations between them as well as with dust, clouds and atmospheric state variables (temperature and others) need to be investigated. In the case of outgassing, sources must be localized and possibly related to (sub) surface composition or mineralogy. Global circulation models with interactive atmospheric chemistry (Neary et al., 2014) will provide support critical to this search.

It is also possible that trace gases are produced in the atmosphere by (photo-)chemical processes or by processes related to dust and/or ice, such as heterogeneous chemistry (Lefevre et al., 2008), triboelectricity (Atreya et al., 2011) or release from polar ices (Atreya et al., 2011). Trace gases may be destroyed by similar processes, through phase transitions or interaction with the regolith or airborne dust (Knak-Jensen et al., 2014).

Specifically for methane, analyses of PFS/MEx NIR spectra revealed high methane abundances in the northern polar region at the end of summer, when the $\mathrm{CO}_{2}$ seasonal ice has completely sublimated and the remnant $\mathrm{H}_{2} \mathrm{O}$-ice cap is exposed (Geminale et al., 2011). The near polar orbit of the spacecraft does not allow for observations beyond $80^{\circ}$ latitude, i.e. the edge of the perma-nent water ice cap (see Fig. 7 which indicates that solar occultation observations will allow probing most latitudes up to $80^{\circ}$, with only a few at higher latitudes, while nadir observations will be restricted to $74^{\circ}$ latitude due to the inclination of the orbit). Nevertheless if NOMAD confirms such a temporal evolution of methane at high northern latitudes, this will provide further evi-dence that the northern perennial ice might be a possible source of methane. The observations of Mumma et al. (2009b) seem rather to indicate release from local sources at low latitudes (Mischna et al., 2011). Lefevre and Forget (2009) provided theoretical evi-dence that the observations by Mumma et al. (2009b) indicate that the lifetime of methane in the Martian atmosphere is heavily reduced compared to the lifetime estimated from standard pho-tochemistry. Similarly, the use of GCM modelling to interpret the NOMAD observations will help to confine the lifetime of $\mathrm{CH}_{4}$ on Mars and will contribute to the search for possible hitherto unknown sinks for $\mathrm{CH}_{4}$.

2.2.3.1. Atmospheric production and loss mechanisms. By measuring aerosols, clouds, surface ices, and vertical temperature profiles, together with $\mathrm{H}_{2} \mathrm{O}$ and HDO, NOMAD will directly assess all the components of the water cycle. In addition $\mathrm{CO}$ and $\mathrm{CO}_{2}$ will be measured simultaneously. Although, no direct measurement of atomic oxygen will be possible, the fact that NOMAD will give access to a wide variety of constituents, will help validate the current understanding that scientists have of the so-called $\mathrm{CO}_{2}$ stability problem. Indeed several catalytic cycles have been proposed to explain why $\mathrm{CO}_{2}$ remains the major component of the Martian atmosphere knowing that it is rapidly destroyed by photolysis and that the direct recombination of its products is negligibly slow (Krasnopolsky and Lefèvre, 2013; McElroy and Donahue, 1972; Parkinson and Hunten, 1972).

This will allow us to investigate important production and loss processes for the major cycles: water, carbon, and dust. More generally, source and sink processes for all trace species measured by NOMAD can be investigated in correlation with each other and with dust, ice and temperature profiles, whether they are related to photochemistry, gas phase chemistry, physical processes (e.g. phase transitions), electrochemical processes in dust storms (triboelectricity), heterogeneous chemistry, or atmosphere-surface/ regolith interaction. The NOMAD team has expertise in terrestrial modelling for ozone destruction (Daerden et al., 2007) through heterogeneous chemistry in a 3D model with detailed online microphysics. This will be extended to the GEM-Mars model (Daerden et al., 2015; Neary et al., 2014) to simulate possible heterogeneous chemistry effects on ozone but also on methane and other species. Routines describing interactions with the sur-face or triboelectricity can also be implemented in GEM-Mars. For more detailed studies involving clouds, the microphysical model developed for the Phoenix mission (Daerden et al., 2010) will be applied. 
2.2.3.2. Localization of sources. The nadir channels of NOMAD have a spatial footprint between 30 and $1000 \mathrm{~km}^{2}$, depending on the integration time. With an almost global sampling of the planet within 7 sols (Martian days), NOMAD will be able to detect any outgassing source region, e.g. plumes of $\mathrm{CH}_{4}$. Slow seeping will likely lead to a more continuous replenishment pattern originating from the same source region.

The localization of sources will be critically supported by 3D model simulations using the GEM-Mars GCM (Daerden et al., 2015). Forward simulations of tracer emissions and plumes will be performed using GEM-Mars (Viscardy et al., 2015). In an ensemble of forward simulations emerging from various source regions and emission scenarios, the most likely source region and scenario can be confined.

Back trajectory calculations will be performed to track back the wind fields from the site of detection to the regions of origin or to specific atmospheric patterns, e.g. local dust storms. The GEM-Mars model has proven its suitability for such calculations (Daer-den et al., 2015). With the Global Variable (mesoscale) non-hydrostatic mode of GEM-Mars (Moudden et al., 2005), simula-tions will be possible down to a scale of $\sim 1 \mathrm{~km} \times 1 \mathrm{~km}$. Other techniques such as inverse modelling (to estimate the emission fluxes), and dynamical data assimilation (to provide improved wind fields by constraining the model calculations using dust and temperature measurements, Lewis et al. (2007)), as well as che-mical data assimilation (Errera et al., 2008; Steele et al., 2014), will also be considered.

The NOMAD SO and LNO solar and limb observations will be of particular interest to search for possible sources in the vertical domain, given their high vertical resolution ( $<1 \mathrm{~km}$ ) by studying correlations of trace gas profiles with profiles of temperature, and with dust layers and ice clouds.

\section{The NOMAD instrument}

NOMAD is a compact, high-resolution, dual channel IR spectrometer (SO and LNO) coupled to a highly miniaturized UVvisible spectrometer (UVIS), capable of operating in different observation modes: solar occultation, nadir and limb. As shown in Fig. 1 , the $-\mathrm{Y}$ face is pointed towards the planet during nadir observation, so that the nadir Lines of Sight (LOS, shown by orange cylinders) point towards the centre of Mars. The Sun pointing LOS (yellow cylinders) are inclined with respect to the nadir direction by $67.07^{\circ}$ through the addition of periscopes protruding from the -

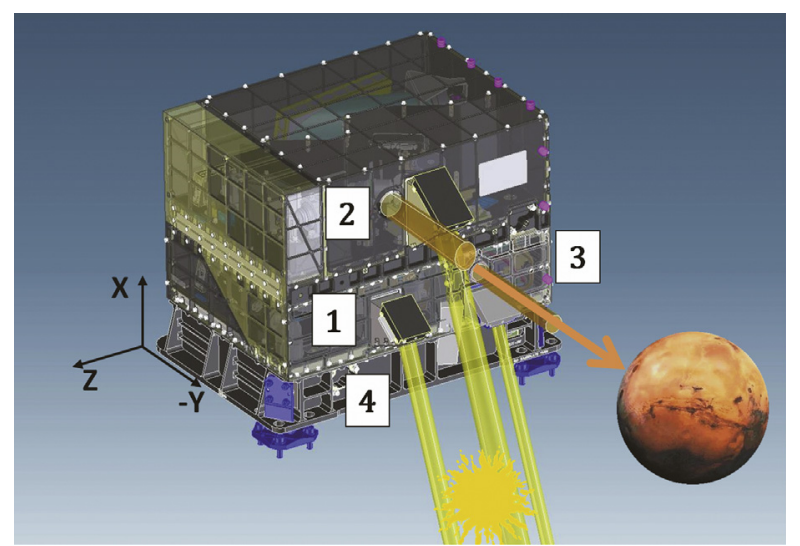

Fig. 1. The NOMAD instrument, with the SO (1), LNO (2) and UVIS (3) channels, and the electronics (4). Lines of sight towards the Sun (yellow cylinders) and the nadir direction (orange cylinders) are also indicated. (For interpretation of the references to color in this figure legend, the reader is referred to the web version of this article.)
Y surface of the instrument. The SO and LNO channels are built upon the SOIR instrument that was developed for the ESA Venus Express mission (Nevejans et al., 2006) and that operated successfully in orbit around Venus until end 2014. Only modest modifications have been introduced for the nadir mode. The UVIS heritage is directly from developments on an instrument which was part of the ExoMars lander. The three channels have each their own optical bench, but share the same single interface to the spacecraft $(S / C)$. In the following each of the channels is described, but we refer to Neefs et al. (2015) and Patel et al. (in preparation) for more technical details on the IR and UVIS channels respectively.

The main characteristics and performances of the 3 channels are summarized in Table 2 . These values will be further described and discussed in the following sections.

\subsection{The SO channel}

The design of the SO channel has been inspired by the existing SOIR instrument (Nevejans et al., 2006), which is part of the SPICAV/SOIR spectrometers suite (Bertaux et al., 2007) on board Venus Express (Svedhem et al., 2007). The SO channel has been optimized for solar occultation observations, i.e. looking at the Sun during sunset and sunrise. It operates at wavelengths between 2.3 and 4.3 $\mu \mathrm{m}$ (2320-4550 $\mathrm{cm}^{-1}$ ), using an echelle grating with a groove density of approximatively 4 lines $/ \mathrm{mm}$ in a near Littrow configuration in combination with an Acousto-Optical Tunable Filter for spectral window selection. Fig. 2 illustrates the schematics of the SO channel. The width of the selected spectral windows varies from 20 to $35 \mathrm{~cm}^{-1}$ depending on the selected diffraction order. The detector is an actively cooled HgCdTe Focal Plane Array and is made up of 320 pixels along the spectral axis and 256 rows. During the ten minutes before an occultation starts, the detector is cooled down to a temperature of about $88 \mathrm{~K}$. SO achieves an instrument line profile resolution of $0.15 \mathrm{~cm}^{-1}$, corresponding to a resolving power $\lambda / \Delta \lambda$ of approximately 20,000 . The slit of the spectrometer is a $2^{\prime}$ (spectral direction) by $30^{\prime}$ (spatial direction) rectangle. The wavenumber range is divided into several diffraction orders, whose definition and limits are presented in Neefs et al. (2015).

The instrument entrance slit is projected on 30 detector rows. Different binning options can be selected depending directly on the number of different AOTF settings that will be used, knowing that at maximum the equivalent of 24 spectra can be downloaded per second. This will be further discussed in the next Section. In most of the observations 6 different values of the AOTF frequency are chosen to record spectra in different spectral intervals per second, hence increasing the number of species potentially detectable quasi-simultaneously. The duration of $1 \mathrm{~s}$ has been chosen as the default cycle of observation performed by SO. It can be changed by telecommand if needed.

\subsection{The LNO channel}

The optical layout of LNO is identical to that of SO (AOTF - echelle spectrometer-cooled detector, see Fig. 3). LNO will be measuring in the wavelength range between 2.3 and $3.8 \mu \mathrm{m}\left(2630-4550 \mathrm{~cm}^{-1}\right)$. To fulfil the Signal to Noise Ratio (SNR) requirement, a number of low risk and easy-to-implement measures were considered to increase the signal throughput as well as to reduce the thermal background of the instrument, e.g. decreasing the highest wavelength limit of the sensitivity of the detector to reduce the impact of thermal noise (from $4.3 \mu \mathrm{m}$ for SO to $3.8 \mu \mathrm{m}$ for $\mathrm{LNO}$ ); increasing the length of the slit from $30^{\prime}$ to $150^{\prime}$; using a larger AOTF crystal, and using longer integration times, appropriate pixel binning, and accumulating spectra. For the LNO channel, the width of the slit has been increased 
Table 2

NOMAD characteristics and performances.

\begin{tabular}{|c|c|c|c|}
\hline & So Channel & LNO Channel & UVIS Channel \\
\hline Detector & 2D HgCdTe $320 \times 256$ pixel FPA & 2D HgCdTe $320 \times 256$ pixel FPA & 2D $1024 \times 256$ pixel CCD \\
\hline Detector temperature & $88 \mathrm{~K}$ & $88 \mathrm{~K}$ & $\mathrm{~N} / \mathrm{A}$ \\
\hline Line of sight & $\begin{array}{l}\text { Periscope lining up with Sun } \\
\text { direction }\end{array}$ & $\begin{array}{l}\text { Periscope for lining up with Sun direction - Nadir view- } \\
\text { ing entrance }\end{array}$ & $\begin{array}{l}2 \text { telescopes lining up with Sun and nadir } \\
\text { directions }\end{array}$ \\
\hline Spectral range & $2.3-4.3 \mu \mathrm{m}$ & $2.3-3.8 \mu \mathrm{m}$ & $200-650 \mathrm{~nm}$ \\
\hline Resolving power & 20,000 & 10,000 & \\
\hline Resolution & $0.15-0.22 \mathrm{~cm}^{-1}$ & $0.3-0.5 \mathrm{~cm}^{-1}$ & $1-2 \mathrm{~nm}$ \\
\hline FOV $($ spectral $\times$ spatial $)$ & $2 \operatorname{arcmin} \times 30 \operatorname{arcmin}$ & $4 \operatorname{arcmin} \times 150$ arcmin & $\begin{array}{l}2 \operatorname{arcmin} \text { (solar occ) } \\
43 \operatorname{arcmin} \text { (nadir) }\end{array}$ \\
\hline Spatial resolution & $1 \mathrm{~km}(\Delta z$ at limb) & $1 \mathrm{~km}(\Delta z$ at limb) & $1 \mathrm{~km}(\Delta z$ at limb) \\
\hline Instantaneous footprint & & $0.5 \mathrm{~km} \times 17 \mathrm{~km}$ & $5 \mathrm{~km} \times 5 \mathrm{~km}$ (Nadir) \\
\hline Vertical sampling & $180 \mathrm{~m}$ to $1 \mathrm{~km}$ & $180 \mathrm{~m}$ to $1 \mathrm{~km}$ & $<300 \mathrm{~m}$ \\
\hline
\end{tabular}

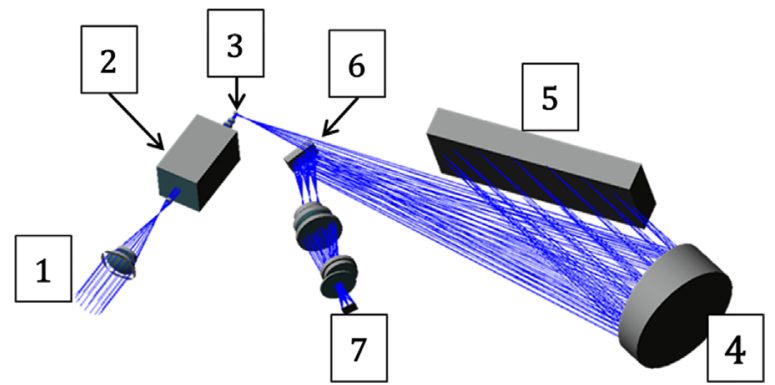

Fig. 2. Schematics of the SO and LNO channels: (1) the entrance optics, (2) the AOTF filter, (3) the spectrometer entrance slit, (4 and 6) folding mirrors, (5) the echelle grating, (7) the detector.

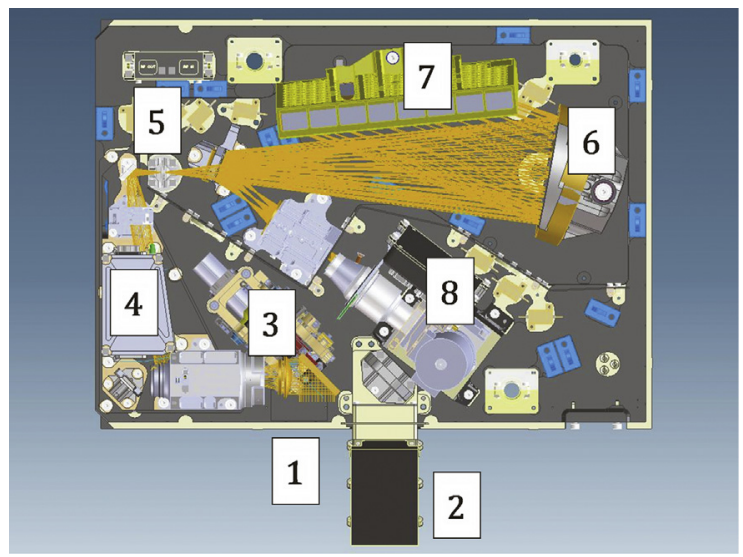

Fig. 3. View of the LNO channel and its components: (1) the entrance optics, (2) the solar occultation periscope, (3) the flip-mirror mechanism, (4) the AOTF filter, (5) the spectrometer entrance slit, (6) the folding mirror, (7) the echelle grating, (8) the detector.

to $4^{\prime}$, leading to a higher throughput and signal to noise ratio (SNR), but a reduction in resolution to $0.3-0.5 \mathrm{~cm}^{-1}$ and a resolving power of $\lambda \mid \Delta \lambda \sim 10,000$.

The detector of LNO is similar to the one chosen for the SO channel $(320 \times 256$ pixels). Since the slit is larger, more rows will be illuminated. For the sake of compatibility in data processing between SO and LNO, also in LNO the equivalent of 24 detector rows can be acquired per measurement cycle. This has a direct impact on the binning possibilities that LNO can access. The different possible combinations for LNO will be further discussed in the next Section.

As for SO, up to 6 different AOTF frequencies can be selected per measurement cycle. Since the light level will be far more reduced when using LNO in nadir mode compared to solar occultation viewing, the integration time is increased. The cycle of

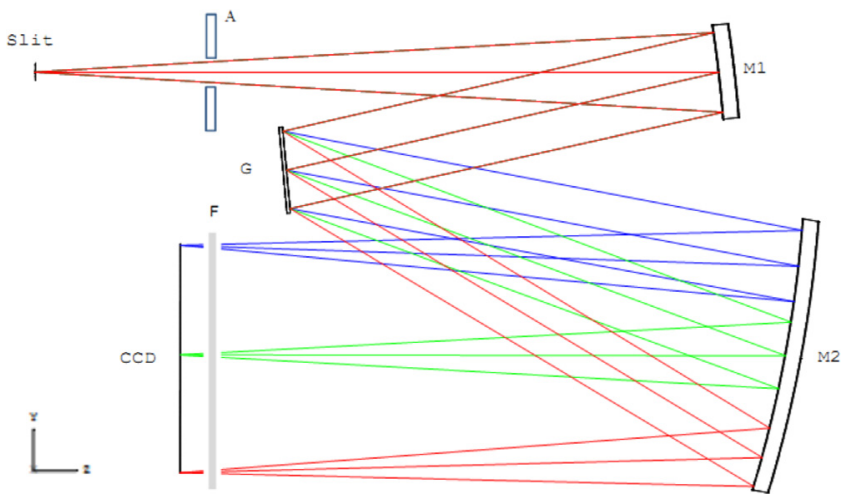

Fig. 4. Schematics of the UVIS instrument: the entrance slit (Slit), the aperture (A) the collimating mirror (M1), the diffraction grating (G), the focusing mirror (M2), the 2nd order filter $(\mathrm{F})$ and the detector (CCD).

LNO has therefore been defined on a $15 \mathrm{~s}$ basis. As for SO, the duration of this cycle can be changed by telecommand.

The LNO channel is equipped with a movable mirror that can be flipped in and out of the optical path. When the mirror is 'in' the optical path, it is pointed towards nadir $(-Y)$. When the mirror is 'out' of the optical path, it is pointed towards the limb and can perform measurements during solar occultations. The flip mirror, that is normally driven by a motor, has a fail-safe system that puts it permanently 'in' the optical path (nadir setting) in case of motor failure.

\subsection{The UVIS channel}

The UVIS channel operates in the wavelength domain between 200 and $650 \mathrm{~nm}$. It is a full copy of the instrument designed for the ExoMars lander, with additional telescopic entrance optics for application in orbit. The spectrometer is based on the conventional Czerny-Turner configuration. The main components of the UVIS channel (see Fig. 4), are the entrance slit, the aperture (A), the collimating mirror (M1), the diffraction grating (G), the focusing mirror (M2), the 2nd order filter (F) and the detector (CCD). The light is delivered by an optical fibre. The spectrometer is an imaging system with a magnification equal to 1 . More details on the instrument can be found in Patel et al. (in preparation). The spectrometer configuration combines simplicity and highperformance. In particular, the spectral range is very broad with optimized performance in the UV range. Blaze angle and incidence angle achieve the highest reflectance of the first diffraction order at $220 \mathrm{~nm}$. The 2nd order filter solves the issue of the overlap between the 1 st diffraction order and the 2 nd diffraction order of the grating. Indeed, due to the wide spectral range of the observed signal, first diffraction order rays and second diffraction order rays 
overlap on the detector. Hence a high-pass filter has been placed in front of the detector to block the second order rays. The slit width is $65 \mu \mathrm{m}$ which corresponds to a spectral resolution better than $1.5 \mathrm{~nm}$. This width results from an optimisation of the resolution and the SNR.

UVIS has one periscope for the solar (narrow field) telescope and a cut out hole in the NOMAD cover for the nadir viewing telescope, see Fig. 5. UVIS switches between nadir and solar viewing angles by alternating which optic fibre cable is placed at the input of the spectrometer - the one coming from the solar telescope (narrow field) or from the nadir telescope (wider angle). The selector mechanism is a rotating motor mechanism qualified on several space missions that drives to two hard stops - one of which is the solar fibre and the other the nadir fibre.

\section{Science implementation}

In the following section we discuss how the NOMAD instrument has been designed to answer the different science objectives that were described in the previous sections. To best answer the questions that still need to be addressed concerning the Mars atmosphere, different observation modes have to be considered. NOMAD will routinely perform solar occultation and nadir observations. Solar occultation observations will provide high vertical resolution ( $<1 \mathrm{~km}$ ) profiles of the structure and composition of the atmosphere, while nadir observations will provide total col-umn maps of the relevant species, allowing the search of sources and sinks. NOMAD is also designed to carry out limb observations although this mode might not be supported by the spacecraft in its baseline definition of operations.

Besides these scientific observational modes, the instrument is also capable of performing a series of calibration and alignment observations. During near-Earth commissioning, cruise phase and in orbit, regular calibration sessions will fine tune the instrument capabilities. These will consist of dark sky observations, and full Sun observations. The latter will help to determine the optimum detector integration time at different wavelengths, to calibrate the wavelength scale by means of solar lines, to characterize the AOTF band pass function (Mahieux et al., 2008, 2009) and to radiometrically calibrate all channels. In the "full Sun" mode the Instrument Lines of Sight (ILS) of all 3 channels are pointed to the centre of the Sun outside the atmosphere. For SO and LNO, a frequency stepping scan over the complete wavelength range is performed, i.e. one step per order. The full solar spectrum, from

2.3 to $3.8 / 4.3 \mu \mathrm{m}$, serves as wavelength calibration reference for observations in the following measurement periods (Mahieux et al., 2010), even if the final calibration of the IR channels relies on the presence of absorption lines of atmospheric constituents (Vandaele et al., 2013).

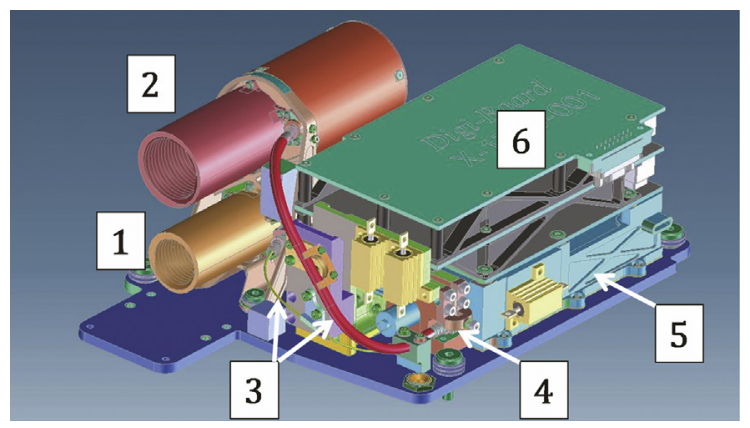

Fig. 5. UVIS channel with the 2 entrance telescopes (1) solar occultation, (2) nadir, the fibers (3), the selector mechanism (4), the main spectrometer (5), and the proximity electronics (6).
Dark sky calibration will be used to verify the thermal background and the non-signal related noise sources. In this mode the ILS of all channels are pointed towards deep space. A series of spectra is recorded, possibly combined, for SO and LNO, with stepping of the different parameters (frequency, integration time, number of accumulations), thus allowing the characterization of the thermal background of the instrument and the detector dark current. SO and LNO channel measurements with the AOTF off offer an alternative for dark sky calibration. The UVIS input selector allows dark calibration without the need for dark sky pointing.

In order to check the alignment of the instrument's ILS with respect to the $\mathrm{S} / \mathrm{C}$ reference frame, as well as with respect to the other Sun looking spectrometer on board (the Atmospheric Chemistry Suite instrument, ACS (Trokhimovsky et al., 2014)), an in-flight "Sun-pointing scan" will be performed occasionally. During a Sun-pointing scan the ILS of the SO, LNO and UVIS channels are pointed to a number of consecutive grid points around and on the solar disk. Based on the intensity profile in each point the misalignment can be calculated between the ILS and the pointing axis of the $\mathrm{S} / \mathrm{C}$. This information will be used to correct the $\mathrm{S} / \mathrm{C}$ pointing.

UVIS always measures a full spectrum, so telecommands only need to specify which optic fibre cable should be positioned at the input of the spectrometer, and to properly select the integration time and pixel binning. UVIS can perform observations with an integration time of $50 \mathrm{~ms}$ to $15 \mathrm{~s}$ (larger values only constrained by footprint size and saturation). To limit data rate when using short integration times, spectra can be accumulated on board to create a higher SNR spectrum of $1 \mathrm{~s}$. If required, spectral binning is also possible.

The dynamic spectral potential of the SO and LNO channels makes it possible to record several different spectral windows, up to 6 , each having a width ranging from 20 to $35 \mathrm{~cm}^{-1}$, in one measurement cycle. This cycle is different for solar occultation and nadir observations because of the levels of light signal that are recorded in these modes and the expected SNR values. Typically, the cycle is of $1 \mathrm{~s}$ for solar occultation and $15 \mathrm{~s}$ for nadir observations. Several species can be retrieved using signatures in one specific window (simultaneous detection) or in different windows (quasi-simultaneous detection).

For the IR channels, the AOTF band pass (width of 22 and $24 \mathrm{~cm}^{-1}$ for the SO and LNO respectively) central wavelength is determined by the radio frequency applied to the transducer. This band width is more or less equal to the width of one order diffracted on the echelle grating. When there is no frequency applied, the AOTF crystal is essentially opaque, meaning that the detector only sees radiation generated after the AOTF (from the slit onwards). This setting can be used to perform background + dark current measurements (hereafter called 'dark' observation), for on-ground subtraction from the measured spectra. One of the 6 spectral domains in each measurement cycle would be dedicated to this dark observation, leaving only 5 domains for atmospheric measurements. Note that while it is possible to not use the dark current setting (and dedicate all frequencies to science regions), this will decrease the accuracy of the background dark current subtraction. Another option is to use half the available measuring time to perform an atmospheric measurement and half for a dark current measurement. This mode is currently used on board SOIR and does not come at the cost of a dark current frequency setting. It does halve the integration time, however, which reduces the SNR.

Each IR channel will carry out an observing loop on a series of maximum six frequencies (from f1 to f6 in Table 3 ) each for the given integration time and number of accumulations, and then cycle back to the first frequency again. 
Table 3

Some examples of solar occultation programming options.

\begin{tabular}{|c|c|c|}
\hline & $\begin{array}{l}\text { From full Sun to an inter- } \\
\text { mediate altitude }\end{array}$ & $\begin{array}{l}\text { From the intermediate altitude } \\
\text { to ground }\end{array}$ \\
\hline Example 1 & $\begin{array}{l}\text { f1: dark }(160 \mathrm{~ms}) \\
\text { f2 to f6: atmosphere }(160 \mathrm{~ms}) \\
\text { no on board subtraction }\end{array}$ & $\begin{array}{l}\text { f7: dark }(160 \mathrm{~ms}) \\
\text { f8 to f12: atmosphere }(160 \mathrm{~ms}) \\
\text { no on board subtraction }\end{array}$ \\
\hline Example 2 & $\begin{array}{l}\text { f1: atmosphere }(1 \mathrm{~s}) \\
\text { with on board subtraction }\end{array}$ & $\begin{array}{l}\text { f7: atmosphere }(1 \mathrm{~s}) \\
\text { with on board subtraction }\end{array}$ \\
\hline Example 3 & $\begin{array}{l}\text { f1: atmosphere }(1 \mathrm{~s}) \\
\text { with on board subtraction }\end{array}$ & $\begin{array}{l}\text { f7: dark }(160 \mathrm{~ms}) \\
\text { f8 to f12: atmosphere }(160 \mathrm{~ms}) \\
\text { no on board subtraction }\end{array}$ \\
\hline Example 4 & f1 to f4: atmosphere $(250 \mathrm{~ms})$ & f7 to f10: atmosphere $(250 \mathrm{~ms})$ \\
\hline
\end{tabular}

Given our experience with SOIR on Venus Express, we have ensured the possibility to switch to a second set of 6 spectral domains at a given moment during the occultation. This means that from the top of the atmosphere down to e.g. $80 \mathrm{~km}$ we can observe more abundant gases or less intense absorption bands and then switch to detection of less abundant gases at an altitude where the optical path is longer and we have more chance of detecting them. AOTF frequency and power, integration time, number of accumulation and binning are typically parameters that might be different with respect to the first set. Examples of pro-gramming options for the IR channels are presented in Table 3 for solar occultation observations.

As described above, a cycle can contain up to 6 spectral domains ( $\mathrm{f} 1$ to $\mathrm{f} 6$ or $\mathrm{f} 7$ to $\mathrm{f} 12$, see Table 3 for some examples), each taking $1 / 6$ th of the cycle time ( $1 \mathrm{~s}$ in solar occultation, $15 \mathrm{~s}$ in nadir observations). If one chooses to use only 4 frequencies, f1 will start at $\mathrm{T} 0$, f2 will start at $\mathrm{T} 0+250 \mathrm{~ms}, \mathrm{f} 3$ will start at $\mathrm{T} 0+500 \mathrm{~ms}$ and $\mathrm{f} 4$ will start at $\mathrm{T} 0+750 \mathrm{~ms}$. To each frequency f1 through f6 or f7 through f12, different parameters can be associated, e.g. integration time, number of accumulations, ... For the example of 4 spectral domains, one could choose to accumulate 24 measurements with $10 \mathrm{~ms}$ integration time, in case the absorption lines and irradiance level are very strong. Summing slightly increases the read-out noise, but reduces the shot noise by the square root of the number of accumulations.

The combination of the number of spectral domains, integration time, number of accumulations and binning, has to remain within the cycle time, especially taking into account the read-out time of the detector for every atmospheric or dark spectrum in the interval.

\subsection{Solar occultation}

The solar occultation mode provides high-resolution vertical profiles of trace gases absolute abundance together with aerosol extinction, pressure, atmospheric density, and temperature at a vertical resolution equal to or lower than $1 \mathrm{~km}$ (in all channels).

In solar occultation mode, the ILS of the channels are pointed to the centre of the Sun. At sunset, recording of spectra starts well before the occultation occurs (the solar spectrum outside the atmosphere is used for referencing), and continues until the lines of sight cross the planet. At sunrise, recording of spectra continues well above the atmosphere to provide the corresponding reference. Transmittances are obtained by dividing the spectra measured through the atmosphere by a reference spectrum recorded outside the atmosphere. In this way, transmittances become independent of instrumental characteristics, such as the absolute response or the ageing of the instrument and in particular of the detector.

The SO or LNO observation strategy in solar occultation is direct heritage from the SOIR instrument on board the ESA Venus Express mission (Vandaele et al., 2008). Since 6 spectral domains can be measured in a typical $1 \mathrm{~s}$ cycle, this provides an integration and/or accumulation time for each of the selected spectral intervals of $160 \mathrm{~ms}$. If needed, the number of selected wavelength intervals can be reduced, thus increasing the integration time for each interval and hence the SNR. A typical series of spectra obtained during such an occultation is presented in Fig. 6 (right panel), covering the region where $\mathrm{CH}_{4}$ main band is located. The limits of the different orders are shown at the top of the plot. Although the observations will be recorded for tangent heights from ground to space $(250 \mathrm{~km})$, the presence of dust will limit the detection of trace gases near the ground. This will highly depend on the dust loading which varies with time and season.

For UVIS, observations are also recorded with a cycle of $1 \mathrm{~s}$. The SNR is optimized by adjusting the integration time of one single measurement and the number of accumulations. The complete spectral domain of UVIS, from 200 to $650 \mathrm{~nm}$ is recorded in one observation. One of the main objectives of UVIS on top of continuing to improve the $\mathrm{O}_{3}$ climatology, is to deliver information on the aerosol content of the Martian atmosphere (see Fig. 6 Left Panel).

The final TGO science orbit should be quasi-circular, at about $380-430 \mathrm{~km}$ above the planet's surface, with an inclination of $74^{\circ}$, an eccentricity of 0.0069 and an argument of pericenter of $270^{\circ}$. The latest orbit calculation has been performed for an orbit such that the ground track closes after 373 orbital revolutions, one orbital period being $2 \mathrm{~h}$ long. NOMAD permits the full exploitation of the orbit. From a $74^{\circ}$ inclined orbit, the latitudes covered in solar occultation range from $87^{\circ} \mathrm{N}$ to $88^{\circ} \mathrm{S}$ with good revisit time at various solar longitudes (see Fig. 7). In Fig. 7, we have distinguished observations performed under different beta angle values: below $60^{\circ}$, between $60^{\circ}$ and $63.46^{\circ}$, and above $63.46^{\circ}$. The beta angle is the angle measured between the Sun vector and the orbital plane of Mars. The $63.46^{\circ}$ value corresponds to an occultation whose lowest altitude sounded is the surface (grazing occultation). The limit of $60^{\circ}$ is imposed by the orbiter, in fact it is remnant of the initial presence of the US MATMOS instrument (Wennberg et al., 2011) that was not capable of observing occultations with beta angle above $60^{\circ}$ because of the long duration of such occultations (longer than $450 \mathrm{~s}$ ). It is clear that latitudes between $\pm 40^{\circ}$ are not sounded very frequently, although the equatorial region of Mars is one of the most dynamically active ones and the main source of atmospheric dust for the summer hemisphere. Together with dust, also trace gas species are expected to be injected here from the boundary layer into the higher atmosphere - it thus serves as an important possible source region of trace gases.

Since UVIS has a circular field of view, and the optical fibres do not transmit spatial information to the detector, only the slit orientation in SO and LNO need clarification. Both slits are fixed with respect to the mechanical axes of the instrument (parallel to the $X$-axis). The image of the slits is projected parallel to the detector columns. The orientation of the slits with respect to Mars therefore depends entirely on TGO. The spacecraft rotation does not allow to align the NOMAD SO (or LNO) slit to be parallel to the limb, as was the case with the SOIR instrument, and the optical solution that would allow internal image rotation was deemed too risky and costly (mass, volume, price).

The TGO spacecraft will use inertial pointing for solar occultations. This means that there is no active spacecraft attitude control during the observations. The spacecraft will perform a slew manoeuvre $5 \mathrm{~min}$ before sunset to move the solar bore sights into 

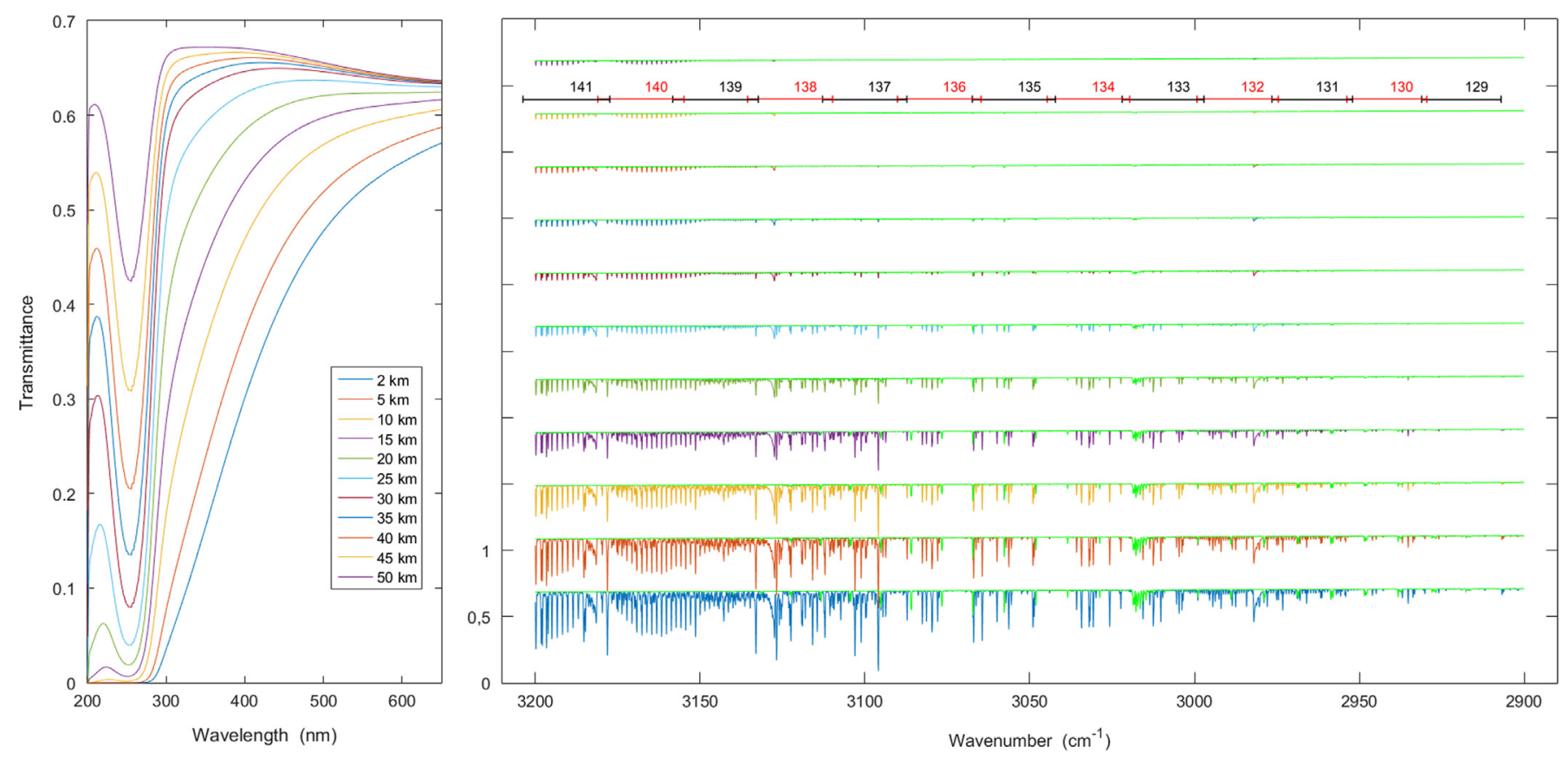

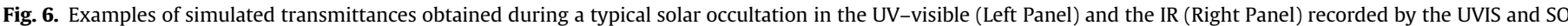

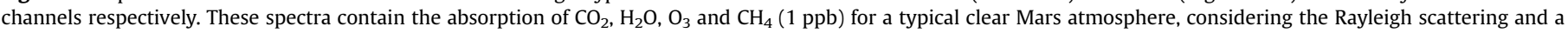

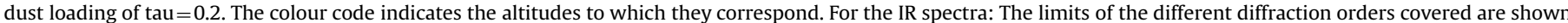

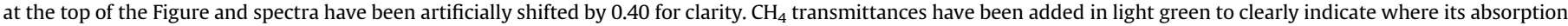
lines are located.

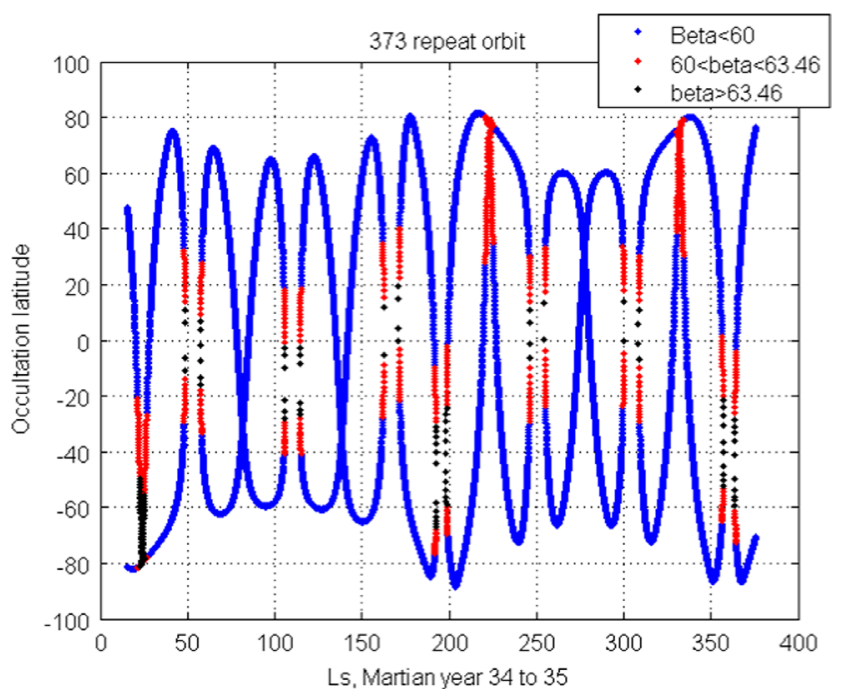

Fig. 7. Latitude of occultations over 1 Martian year for various beta angles. It is clear that being able to observe the red marked occultations between beta angles 60 and 63.46 would greatly increase the NOMAD coverage.

position and allow for stabilisation of the platform before the start of observations. Once in position, the slit angle will 'drift' into a perpendicular orientation with respect to the limb, and out again, as shown in Fig. 8. The altitude at which the slit becomes perpendicular to the limb is currently set at $30 \mathrm{~km}$ above the surface. This value was chosen to maximize resolution at lower altitudes where more trace gases will be observed. Although the spatial resolution will depend on the verticality of the slit, the main factor influencing the resolution is the binning.

The instantaneous fields of view (IFOV) of both IR channels are limited by the apparent size of the solar disk $\left(21^{\prime}\right)$ and by the slit width ( $2^{\prime}$ for SO and $4^{\prime}$ for LNO, the long side of the slit being

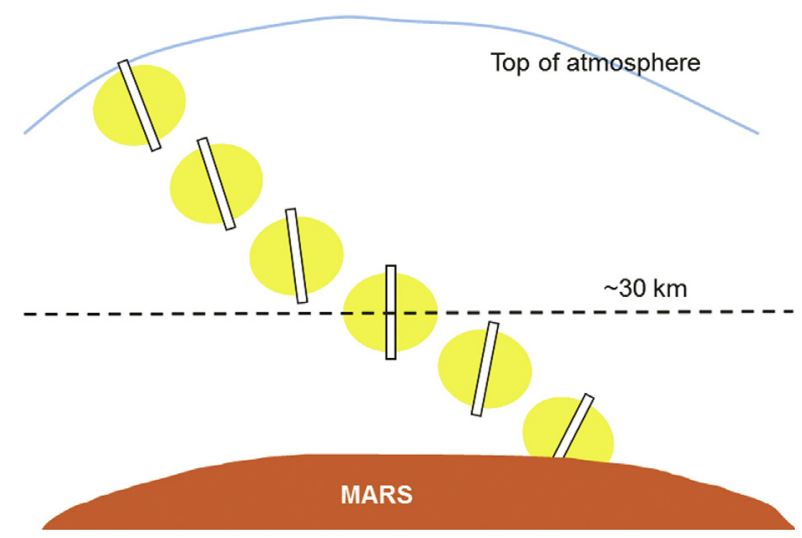

Fig. 8. Evolution of the slit angle during a typical occultation (inclination exaggerated for clarity)

perpendicular to the limb), whereas for UVIS it is only limited by the size of the aperture ( $2^{\prime}$ circular). The instantaneous fields of view of the SO and LNO slits at the limb are thus $1 \times 12 \mathrm{~km}^{2}$ and $2 \times 12 \mathrm{~km}^{2}$ respectively. However the vertical resolution and sampling are governed by the number of rows binned, as explained in Table 4. A total of 24 spectra can be transmitted to Earth per cycle of observation. This is a downlink limitation. So if 6 different wavelength intervals are recorded, only 4 spectra per such interval can be downloaded. As shown in the Table, this can be 4 single rows, 8 rows binned by 2, or all 24 rows illuminated binned by 6 . The instantaneous field of view of each of these spectra corresponding to one bin varies from $0.5 \mathrm{~km}$ (single rows) to $3 \mathrm{~km}$ (24 rows binned by 6 ). Binning 2 rows into one spectrum for download ensures the $1 \mathrm{~km}$ resolution promised by NOMAD. The maximum vertical descent velocity of $1.2 \mathrm{~km} / \mathrm{s}$ will delineate 
the sampling rate and the final FOV, as illustrated in Fig. 9. For an offset angle $\alpha$ of $20^{\circ}$ the $3 \mathrm{~km}$ IFOV becomes $3 / \cos \alpha=3.20 \mathrm{~km}$. The maximum vertical displacement of $1.2 \mathrm{~km}$ in a second means that

Table 4

The instantaneous field of view of each spectrum for SO compared to the number of rows binned to make that spectrum, for the baseline concept of 6 frequencies per observation.

\begin{tabular}{|c|c|c|c|}
\hline \# of IR frequencies & $\begin{array}{l}\text { \# of IR spectra } \\
\text { /frequency Max } \\
\text { integ time }\end{array}$ & $\begin{array}{l}\text { Rows read-out } \\
\text { from IR } \\
\text { detector }\end{array}$ & $\begin{array}{l}\text { SO IFOV of } \\
\text { each spectrum }\end{array}$ \\
\hline \multirow[t]{5}{*}{$\begin{array}{l}6 \text { (baseline, with } 1 \text { of } \\
\text { these a 'dark' } \\
\text { setting) }\end{array}$} & 4 & $\begin{array}{l}4 \text { single rows } \\
8 \text { rows binned } \\
\text { by } 2\end{array}$ & $\begin{array}{l}0.5 \mathrm{~km} \\
1 \mathrm{~km}\end{array}$ \\
\hline & & $\begin{array}{l}12 \text { rows binned } \\
\text { by } 3\end{array}$ & $1.5 \mathrm{~km}$ \\
\hline & $160 \mathrm{~ms}$ & $\begin{array}{l}16 \text { rows binned } \\
\text { by } 4\end{array}$ & $2 \mathrm{~km}$ \\
\hline & & $\begin{array}{l}20 \text { rows bin- } \\
\text { ned by } 5\end{array}$ & $2.5 \mathrm{~km}$ \\
\hline & & $\begin{array}{l}24 \text { rows bin- } \\
\text { ned by } 6\end{array}$ & $3 \mathrm{~km}$ \\
\hline
\end{tabular}

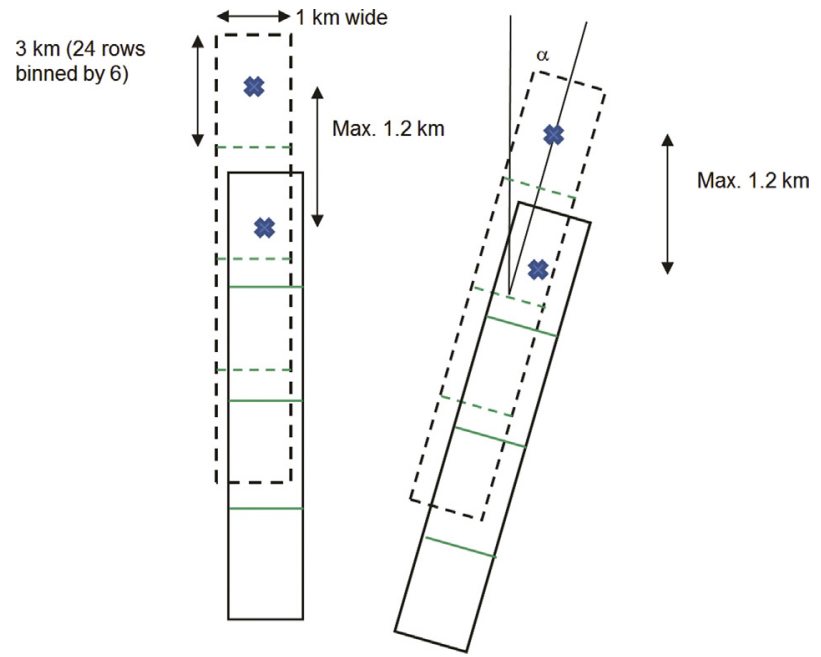

Fig. 9. Representation of a perpendicular and off-perpendicular slit of the SO channel (not to scale): in dashed line at time $t_{0}$ and in plain at time $t_{0}+1 \mathrm{~s}$, considering a $1 \mathrm{~s}$ cycle and a maximum downward velocity of $1.2 \mathrm{~km}$. there is overlap between bins sampled in consecutive measurements of the same spectral window.

\subsection{Nadir observations}

The instantaneous field of view of the LNO slit $\left(4^{\prime} \times 144^{\prime}\right)$ corresponds to a footprint of $0.5 \times 17 \mathrm{~km}^{2}$, and that of UVIS $\left(43^{\prime}\right)$ to 5 $\times 5 \mathrm{~km}^{2}$. The velocity of the spacecraft is approximately $3.4 \mathrm{~km} / \mathrm{s}$ projected on the ground (3386 km Mars radius, altitude $400 \mathrm{~km}$, orbital period $7100 \mathrm{~s}$ ). So, in $15 \mathrm{~s}$ the slit moves $51 \mathrm{~km}$ across the surface. The nadir observation mode therefore provides vertical columns with spatial footprints varying from $0.5 \times 68 \mathrm{~km}^{2}$ up to 17 $\times 51 \mathrm{~km}^{2}$ for LNO and of $5 \times 56 \mathrm{~km}^{2}$ for UVIS (for observation time $\sim 15 \mathrm{~s}$ ). As the $\mathrm{CO}_{2}$ column abundance is retrieved at the same time, systematic error sources are eliminated and mixing ratios will be determined.

The ILS of the LNO and UVIS channels are pointed towards the centre of Mars. UVIS records spectra in the same domain as in solar occultation. The LNO channel has the same operational flexibility as for solar occultation observations, i.e. up to 6 AOTF settings in one cycle. This allows different scenarios to be set-up. For example if only one spectral window (one AOTF frequency) is selected, the complete cycle is dedicated to this spectral window and can consist of one or more spectra accumulated during the cycle. This strategy will be used for nominal $\mathrm{CH}_{4}$ observations. The selected AOTF frequency corresponds to the spectral interval $\left(3014-3041 \mathrm{~cm}^{-1}\right)$ that contains the $\mathrm{Q}$ branch and the $\mathrm{R}(0)$ line of

the $\nu_{3}$ band of $\mathrm{CH}_{4}$ (Robert et al., in preparation). Using this setting, $\mathrm{CH}_{4}, \mathrm{H}_{2} \mathrm{O}$ and $\mathrm{CO}_{2}$, which have absorption lines in the same wavelength interval, will be obtained simultaneously. But several spectral windows can be selected, each being dedicated to one or more target species. Then the windows are integrated one after the other on the detector during a specified integration time. This hopping strategy allows the creation of a patchwork of successive footprints devoted for example to $\mathrm{CH}_{4} / \mathrm{H}_{2} \mathrm{O} / \mathrm{CO}_{2}, \mathrm{H}_{2} \mathrm{O} / \mathrm{HDO}, \mathrm{CO}$, $\mathrm{C}_{2} \mathrm{H}_{2}$, then back again to $\mathrm{CH}_{4} / \mathrm{H}_{2} \mathrm{O} / \mathrm{CO}_{2}$, and so on.

The nadir coverage between $\pm 74^{\circ}$ latitude provides global spatial sampling on average every 3 to 4 sols with varying local times. Due to the nature of the orbit, there will be occasional repeated ground tracks offering better temporal sampling of a given region. Fig. 10 illustrates the repeatability of the ground track after 4 and 7 sols.

During nadir observations, LNO and the UVIS nadir telescope will observe the ground track 'underneath' the satellite for a specified integration time. In order to keep the radiator face away
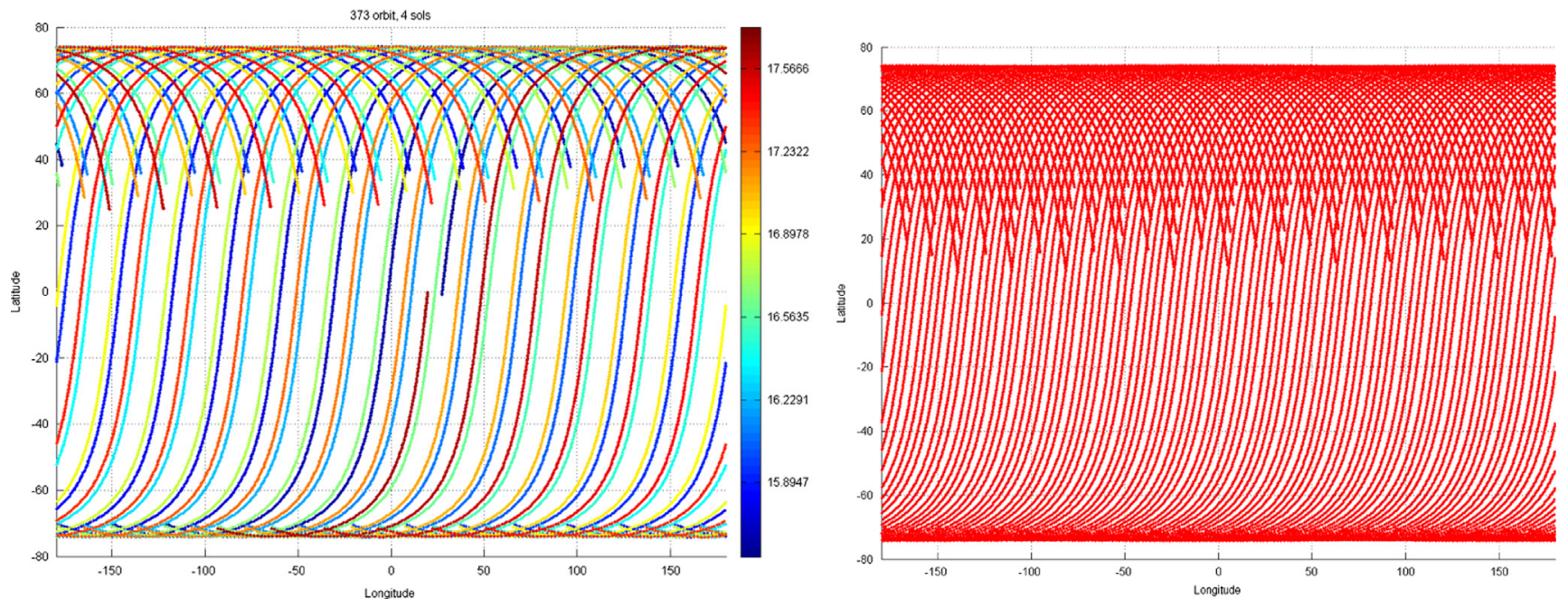

Fig. 10. Groundtrack after 4 sols (Left) and 7 sols (Right). 
from the Sun and the solar panels in maximum illumination, TGO rotates around its nadir-pointed axis ( $-Y$-axis, see Fig. 1$)$. This will rotate the LNO slit with respect to the ground track (the UVIS instantaneous footprint is circular and is therefore not impacted by this rotation). For a beta $(\beta)$ angle of 0 , the slit will be parallel to the ground track once the spacecraft has slewed into nadir pointing position, perpendicular at the equator, and back to par-allel at the other pole. The footprint traced out by the slit on the surface will therefore change significantly in size. When the slit projection is perpendicular to the ground track, the LNO footprint corresponding to a $15 \mathrm{~s}$ measurement time is $17 \times 51.5 \mathrm{~km}^{2}$, whilst when it is parallel to the ground track, it is $0.5 \times 68 \mathrm{~km}^{2}$. For $\beta$ of $90^{\circ}$ (where the TGO orbit is over the terminator at all times) the slit is perpendicular to the ground track at all times (thus, in theory half on the sunlit side and half on the dark side). For intermediate beta angles, the situation is between these two extremes. Fig. 11 shows a super-enlarged slit for $\beta=0^{\circ}$ (TGO is looking at the day side of Mars) with respect to the ground track. For the footprint of the slit at intermediate angles, we have cal-culated the area of the parallelogram swept out by the slit with the motion of the spacecraft (assuming the angle does not change significantly during the measuring time of $15 \mathrm{~s}$ ). This is shown in Fig. 12.

\subsection{NOMAD expected performances}

A preliminary sensitivity study (Drummond et al., 2011) was carried out to assess the detection limits using a SOIR-type instrument for solar occultation and nadir at Mars. This showed that methane concentrations below $1 \mathrm{ppb}$ can be detected from just one spectrum, for a signal to noise ratio based on the SNR values currently observed with SOIR/VEx (Mahieux et al., 2009). Using the latest optical models of the three NOMAD channels (Thomas et al., in preparation; Vandaele et al., submitted for publication), signal to noise ratios achievable under the current best and optimized laboratory characterization have been inves-tigated and updated detection limits have been determined (Robert et al., in preparation). Note however that these are still models that might be modified once calibration, either in the laboratory or in flight, will have been performed. We have

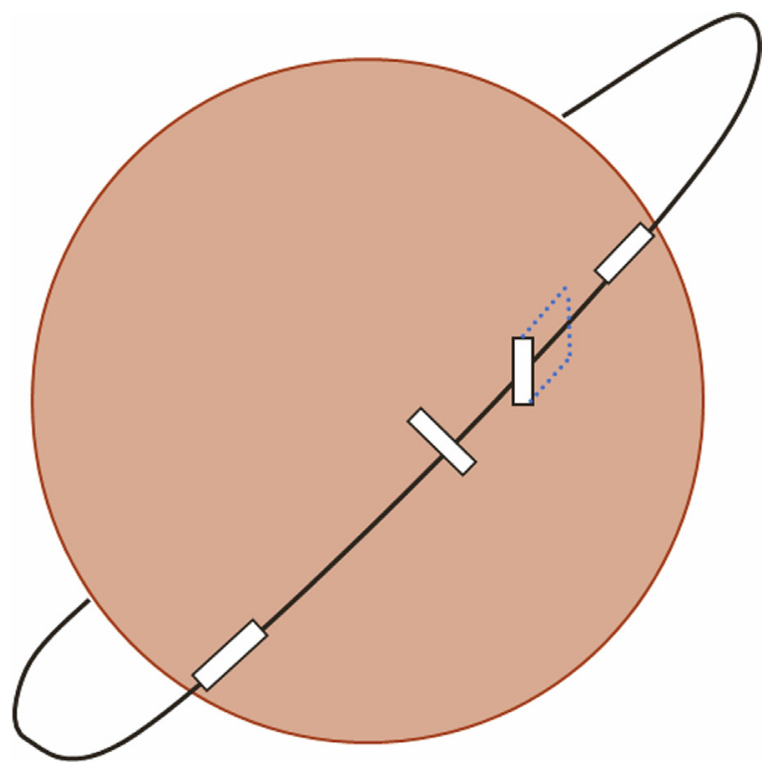

Fig. 11. A representation of the evolution of the slit angle w.r.t the ground track for beta angle $=0^{\circ}$. The blue dashed parallelogram shows the area swept out during an integration time. This image is not to scale. The view is from the Sun, the disk is then the day side of the planet, and the circle circumference is the terminator.

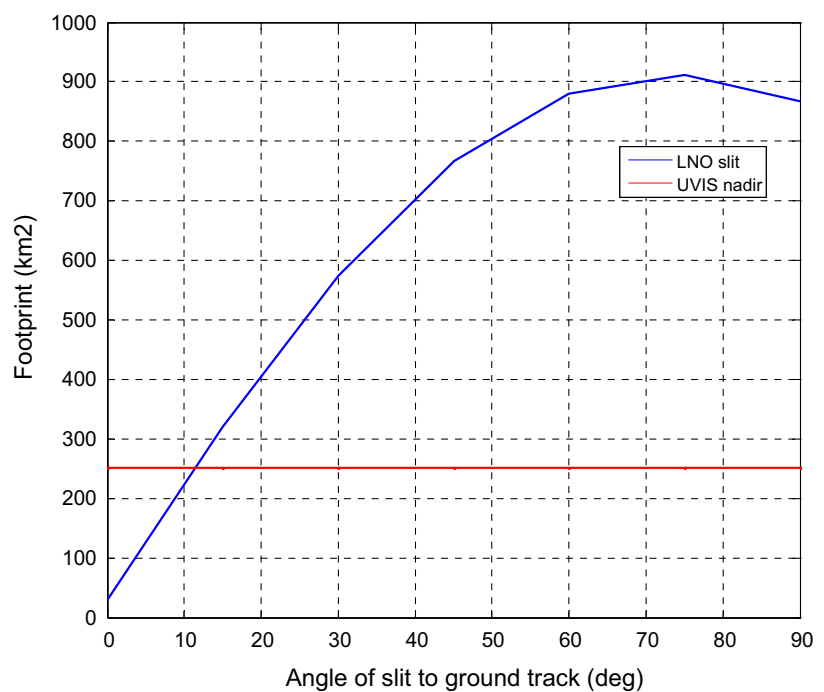

Fig. 12. Evolution of the footprint area (square $\mathrm{km}$ ) evolves with the angle with respect to the ground track.

therefore taken the worst cases analysis into consideration in the following, expecting improvement of the numbers after due calibration.

For SO, the detection limits have been determined assuming a one-second cycle with 6 different spectral windows of $160 \mathrm{~ms}$ and a spectral resolution of $0.15 \mathrm{~cm}^{-1}$. The detailed SNR study (Thomas et al., in preparation) reveals that for typical conditions, values between 2800 (at $3.2 \mu \mathrm{m}$ ) and 2000 (at $4.0 \mu \mathrm{m}$ ) are obtained. Note that playing with the number of accumulations (maximum 16 in this case) and the binning of rows (6 at maximum), the SNR can still be improved by factors of 4 and 2.5 respectively. The detection limits indicated in Table 5 have been obtained for a SNR value of 2000. As explained in Robert et al. (in preparation) this low value has been chosen in order to remain very conservative and covering the impact of the dust. For the LNO channel observing in solar occultation, the hypotheses were similar and a SNR value of 3000 has been considered for the determination of the detection limits in solar occultation with LNO. The investigation has been performed on a wide range of selected targets.

The sensitivity study was also performed for LNO nadir observations. Initially a passive cryo-radiator was proposed to decrease the operational temperatures of the channel, along with that of UVIS. This cryo-radiator would have cooled down part of the spectrometer from the slit to the detector window down to $173 \mathrm{~K}$. The detector of LNO itself sits in a Dewar and is coupled to an active cooler that brings the detector temperature down to $88 \mathrm{~K}$ to limit the noise generated by the detector itself. Due to mass con-straints the passive radiator had to be de-scoped from the instrument. This had a clear impact on the detection limits of the LNO channel. This has a clear impact on the thermal radiation which is emitted by any single surface in relation to its tempera-ture. The SNR considered in the preliminary study (Drummond et al., 2011) assumed the presence of the cryo-cooler, and differ-ences between the then derived detection limits and the results of this work, mainly arise from the removing of this radiator. The detailed SNR analysis performed on LNO nadir considered the contribution of the Sun radiation reflected on the planet's surface under different Martian conditions: when Mars is at aphelion (farthest away from the Sun) or at perihelion (closest to the Sun), considering different surface albedos, different angles of the Sun illumination, and different dust loadings (Thomas et al., in 
Table 5

NOMAD detection limits for the three channels in solar occultation and nadir geometry.

\begin{tabular}{|c|c|c|c|c|c|c|}
\hline \multirow[t]{3}{*}{ Species } & \multirow[t]{3}{*}{ Current Knowledge } & \multicolumn{5}{|l|}{ Detection limits } \\
\hline & & \multirow{2}{*}{$\begin{array}{l}\text { SO } \\
\text { Solar Occultation } \\
(\mathrm{SNR}=2000)\end{array}$} & \multicolumn{2}{|l|}{ LNO } & \multicolumn{2}{|l|}{ UVIS } \\
\hline & & & $\begin{array}{l}\text { Solar Occultation } \\
(\mathrm{SNR}=3000)\end{array}$ & $\begin{array}{l}\text { Nadir } \\
(S N R=100)\end{array}$ & $\begin{array}{l}\text { Solar Occultation } \\
(\mathrm{SNR}=500)\end{array}$ & $\begin{array}{l}\text { Nadir } \\
(\mathrm{SNR}=500)\end{array}$ \\
\hline $\mathrm{O}_{3}$ & & $2.5 \mathrm{ppb}$ & $1.5 \mathrm{ppb}$ & $0.8 \mathrm{ppm}$ & $50 \mathrm{ppt}$ & $4.5 \mathrm{ppb}$ \\
\hline $\mathrm{CH}_{4}$ & $0-60 \mathrm{ppb}^{\mathrm{a}}$ & $25 \mathrm{ppt}$ & $20 \mathrm{ppt}$ & $11 \mathrm{ppb}$ & & \\
\hline $\mathrm{H}_{2} \mathrm{O}$ & $<300 \mathrm{ppm}$ (variable with season) $)^{\mathrm{b}}$ & $0.2 \mathrm{ppb}$ & $0.15 \mathrm{ppb}$ & $31 \mathrm{ppb}$ & & \\
\hline HDO & $\mathrm{D} / \mathrm{H}=5.6 \mathrm{SMOW}^{\mathrm{c}}$ & $0.7 \mathrm{ppb}$ & $0.7 \mathrm{ppb}$ & $0.8 \mathrm{ppm}$ & & \\
\hline $\mathrm{CO}$ & $700-800 \mathrm{ppm}^{\mathrm{d}}$ & $5 \mathrm{ppb}$ & $4 \mathrm{ppb}$ & $1.5 \mathrm{ppm}$ & & \\
\hline $\mathrm{C}_{2} \mathrm{H}_{2}$ & $<2 \mathrm{ppb}^{\mathrm{e}}$ & $0.03 \mathrm{ppb}$ & $0.03 \mathrm{ppb}$ & $20 \mathrm{ppb}$ & & \\
\hline $\mathrm{C}_{2} \mathrm{H}_{4}$ & $<4 \mathrm{ppb}^{\mathrm{e}}$ & $0.2 \mathrm{ppb}$ & $0.15 \mathrm{ppb}$ & $70 \mathrm{ppb}$ & & \\
\hline $\mathrm{C}_{2} \mathrm{H}_{6}$ & $\begin{array}{l}<0.2 \mathrm{ppb}^{\mathrm{f}} \\
<0.7 \mathrm{ppb}^{\mathrm{e}}\end{array}$ & $0.03 \mathrm{ppb}$ & $0.02 \mathrm{ppb}$ & $11 \mathrm{ppb}$ & & \\
\hline $\mathrm{HCl}$ & $\begin{array}{l}<3 \mathrm{ppb}^{\mathrm{f}} \\
<0.2 \mathrm{ppb}^{\mathrm{g}} \\
<0.6 \mathrm{ppb}^{\mathrm{e}}\end{array}$ & $0.03 \mathrm{ppb}$ & $0.025 \mathrm{ppb}$ & $31 \mathrm{ppb}$ & & \\
\hline $\mathrm{HCN}$ & $<5 \mathrm{ppb}^{\mathrm{e}}$ & $0.03 \mathrm{ppb}$ & $0.03 \mathrm{ppb}$ & $15 \mathrm{ppb}$ & & \\
\hline $\mathrm{H}_{2} \mathrm{CO}$ & $\begin{array}{l}<4.5 \mathrm{ppb}^{\mathrm{f}} \\
<3.9 \mathrm{ppb}^{\mathrm{e}}\end{array}$ & $0.04 \mathrm{ppb}$ & $0.03 \mathrm{ppb}$ & $16 \mathrm{ppb}$ & $7.5 \mathrm{ppb}$ & $150 \mathrm{ppb}$ \\
\hline $\mathrm{HO}_{2}$ & $\begin{array}{l}0.1-6 \mathrm{ppb}^{\mathrm{h}} \\
<200 \mathrm{ppb}^{\mathrm{e}}\end{array}$ & $1 \mathrm{ppb}$ & $1 \mathrm{ppb}$ & $0.5 \mathrm{ppm}$ & & \\
\hline $\mathrm{H}_{2} \mathrm{~S}$ & $\begin{array}{l}<200 \mathrm{ppm}^{\mathrm{i}} \\
<1.3 \mathrm{ppb}^{\mathrm{j}}\end{array}$ & $4 \mathrm{ppb}$ & $3 \mathrm{ppb}$ & 1.6 ppm & & \\
\hline $\mathrm{N}_{2} \mathrm{O}$ & $\begin{array}{l}<100 \mathrm{ppb}^{\mathrm{i}} \\
<90 \mathrm{ppb}^{\mathrm{e}}\end{array}$ & $0.2 \mathrm{ppb}$ & $0.2 \mathrm{ppb}$ & $83 \mathrm{ppb}$ & & \\
\hline $\mathrm{NH}_{3}$ & $\begin{array}{l}<5 \mathrm{ppb}^{\mathrm{i}} \\
<60 \mathrm{ppb}^{\mathrm{e}}\end{array}$ & & & & $1 \mathrm{ppb}$ & - \\
\hline $\mathrm{NO}_{2}$ & $<10 \mathrm{ppb}^{\mathrm{i}}$ & $0.14 \mathrm{ppb}$ & $0.1 \mathrm{ppb}$ & 50 ppb & & \\
\hline OCS & $<10 \mathrm{ppb}^{\mathrm{i}}$ & $0.3 \mathrm{ppb}$ & $0.3 \mathrm{ppb}$ & $122 \mathrm{ppb}$ & & \\
\hline $\mathrm{SO}_{2}$ & $\begin{array}{l}<1 \mathrm{ppb}^{\mathrm{k}} \\
<2 \mathrm{ppb}^{\mathrm{l}, \mathrm{m}} \\
<0.3 \mathrm{ppb}^{\mathrm{n}} \\
<1.1 \mathrm{ppb}^{\mathrm{j}}\end{array}$ & & & & $0.5 \mathrm{ppb}$ & $18 \mathrm{ppb}$ \\
\hline
\end{tabular}

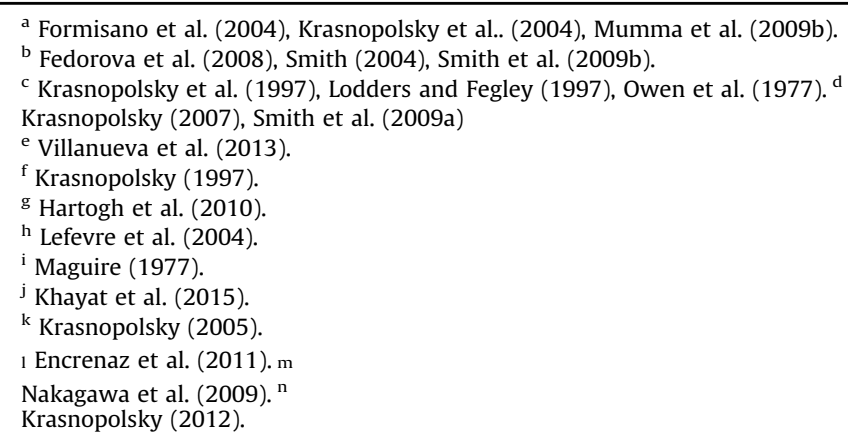

preparation). Again to remain on a very conservative value, a SNR of 100 has been considered in the following.

The detection limits have been determined for UVIS considering a SNR of 500 for both viewing geometries (Vandaele et al., submitted for publication), although the detailed analysis showed that SNR values up to 6000 could be achieved for wavelengths higher than $300 \mathrm{~nm}$. Below that limit, the SNR drops very fast.

From Table 5, NOMAD is expected to improve drastically the knowledge of the composition of the Martian atmosphere. Indeed the detection limits for several species will be improved in some cases by more than a factor 10 .

\subsubsection{Formaldehyde $\left(\mathrm{H}_{2} \mathrm{CO}\right)$}

On Mars the photochemical lifetime of $\mathrm{H}_{2} \mathrm{CO}$ is short ( $7.5 \mathrm{~h}$ ) leading to low predicted abundances if its production is governed by the $\mathrm{CH}_{4}$ oxidation. However if biogenic release exists, then the $\mathrm{H}_{2} \mathrm{CO}$ level should be comparable to that of methane. $\mathrm{H}_{2} \mathrm{CO}$ was first claimed to have been detected in the IR Phobos spectra obtained in solar occultation (Korablev et al., 1993), although later reanalysis showed that the observed structure assigned to $\mathrm{H}_{2} \mathrm{CO}$ was in fact an instrumental artefact (Korablev, 2002). Krasnopolsky (1997) reported an upper limit of $4.5 \mathrm{ppb}$ using high-resolution ground-based IR spectrometer. Recently, Villanueva et al. (2013) performed a detailed sensitive search for organics in Mars spectra and found an upper limit of $3.9 \mathrm{ppb}$.

\subsubsection{Acetylene $\left(\mathrm{C}_{2} \mathrm{H}_{2}\right)$, ethylene $\left(\mathrm{C}_{2} \mathrm{H}_{4}\right)$ and ethane $\left(\mathrm{C}_{2} \mathrm{H}_{6}\right)$}

Measurement of such organics are believed to help distinguish between biology vs. geology production schemes: on Earth low $\mathrm{CH}_{4} / \mathrm{C}_{2} \mathrm{H}_{6}$ ratios are representative of thermogenic sources, whereas high ratios indicate a biogenic origin of $\mathrm{CH}_{4}$ (Allen et al., 2006). $\mathrm{C}_{2} \mathrm{H}_{6}$ can also be produced hydrogeochemically through the serpentization of silicates and its detection would then indicate a geochemical source of methane. Such compounds are low in abundance, but if they are largely produced by photo-dissociation and oxidation of $\mathrm{CH}_{4}$ (Wong et al., 2004b), then their detection would provide a confirmation of the presence of $\mathrm{CH}_{4}$. These are short-lived species and their detection would moreover constrain the source of methane. Upper limits were reported by Maguire (1977) (2500 and $400 \mathrm{ppb}$ for $\mathrm{C}_{2} \mathrm{H}_{2}, \mathrm{C}_{2} \mathrm{H}_{4}$ and $\mathrm{C}_{2} \mathrm{H}_{6}$ respectively), 
Krasnopolsky (2012) (0.2 ppb for ethane) and Villanueva et al. (2013) (6, 4 and $0.7 \mathrm{ppb}$ for $\mathrm{C}_{2} \mathrm{H}_{2}, \mathrm{C}_{2} \mathrm{H}_{4}$ and $\mathrm{C}_{2} \mathrm{H}_{6}$ respectively).

\subsubsection{Hydroperoxyl $\left(\mathrm{HO}_{2}\right)$}

$\mathrm{HO}_{2}$ has been predicted by models to be within the 0.1-6 ppb range (Lefevre et al., 2004) but no detection could confirm these values. Villanueva et al. (2013) reported an upper limit of $200 \mathrm{ppb}$.

\subsubsection{Nitrogen family $\left(\mathrm{N}_{2} \mathrm{O}, \mathrm{HCN}, \mathrm{NH}_{3}\right)$}

$\mathrm{N}_{2}$ is the second most abundant gas in the atmosphere of Mars. It is thought to be the main nitrogen reservoir in the atmosphere, $\mathrm{NH}_{3}$ and $\mathrm{N}_{2} \mathrm{O}$ being rapidly photolyzed. Recent observations of nitrogen in sedimentary and Aeolian deposits by the Curiosity rover (Stern et al., 2015) has important implications for the potential evolution of a nitrogen cycle in the Martian history. The bulk of $\mathrm{N}$ detected by Curiosity was in the form of nitric oxide (NO) and may indicate a sink for atmospheric $\mathrm{N}_{2}$ in the form of nitrate, with an estimated abundance of up to $1100 \mathrm{ppm} \mathrm{NO}-$ in Martian deposits. $\mathrm{N}_{2} \mathrm{O}$ detection could be an indication of recent outgassing from a sub-surface source. Moreover $\mathrm{N}_{2} \mathrm{O}$ can be produced by bacteria in anoxic environments and sub-surface colonies of microbes that could produce $\mathrm{CH}_{4}$ could also release $\mathrm{N}_{2} \mathrm{O}$. $\mathrm{HCN}$ is not expected to be produced in a $\mathrm{CO}_{2}$ atmosphere, and its detection could only be an indicator from sub-surface primordial material. Maguire (1977) reported an upper limit for $\mathrm{NH}_{3}$ of $5 \mathrm{ppb}$ and Villanueva et al. (2013) values of 90 ppb, 5 ppb and $60 \mathrm{ppb}$ for $\mathrm{N}_{2} \mathrm{O}, \mathrm{HCN}$ and $\mathrm{NH}_{3}$ respectively.

\subsubsection{Sulphur family $\left(\mathrm{SO}_{2}, \mathrm{H}_{2} \mathrm{~S}, \mathrm{OCS}\right)$}

No sulphur-bearing species has ever been detected in the Martian atmosphere to date. Sulphur might be the signature of ongoing outgassing activity. Along with water vapour and $\mathrm{CO}_{2}, \mathrm{SO}_{2}$ is the most abundant gas released by volcanoes on Earth. Finding $\mathrm{SO}_{2}$ on Mars would be a strong indication of volcanic activity. Moreover the $\mathrm{CH}_{4} / \mathrm{SO}_{2}$ ratio could provide a constraint on the origin of the emission, since on Earth large ratios are observed in the context of volcanic eruptions. Since the lifetime of $\mathrm{SO}_{2}$ is short, the detection of $\mathrm{SO}_{2}$ would indicate a recent and localized source. A detection limit of 1 ppb has been obtained by Krasnopolsky (2005) using the Texas Echelon Cross Echelle Spectrograph (TEXES) on the NASA Infrared Telescope Facility (IRTF) and of $2 \mathrm{ppb}$ by Encrenaz et al. (2011) using the same TEXES instrument with optimized observation conditions and by Nakagawa et al.(2009) using heterodyne spectroscopy. Recently Krasnopolsky (2012) refined his detection limits to $0.3 \mathrm{ppb}$. Upper limits of $10 \mathrm{ppb}$ and $100 \mathrm{ppb}$ were obtained for OCS and $\mathrm{SO}_{2}$ by Maguire (1977) using the Mariner 9 IR spectrometer. More recently, Khayat et al. (2015) derived upper limits for $\mathrm{SO}_{2}(1.1 \mathrm{ppb})$ and $\mathrm{H}_{2} \mathrm{~S}(1.3 \mathrm{ppb})$ from ground-based observations of the Tharsis region in the submillimetre region.

\subsubsection{Chlorine species $(\mathrm{HCl})$}

$\mathrm{HCl}$ is thought to be most abundant reservoir of chlorine on Mars. Its detection should identify the source from the surface and constrain the $\mathrm{Cl}$ exchange between the surface and the atmosphere. The Phoenix mission detected high abundance of perchlorate $\mathrm{ClO}_{4}$ (Hecht et al., 2009). Considering the oxidizing characteristics of the Martian atmosphere, perchlorates are expected to be stable under the cold conditions on Mars. Their origin is however still unknown. Early volcanic activity could have produced high abundances of $\mathrm{HCl}$ converted later to perchlorates. Uplifting of fine perchlorate dust could entrain these particles at altitudes where they could undergo further (photo)-chemical transformation creating a source of chlorine in the atmosphere. Krasnopolsky (1997) provided an upper limit for $\mathrm{HCl}$ of $3 \mathrm{ppb}$ from observations performed at the Kitt Peak National Observatory;
Hartogh et al. (2010) found a upper limit of $0.2 \mathrm{ppb}$ using the Herschel/HIFI instrument; Villanueva et al. (2013) reported a upper limit of $0.6 \mathrm{ppb}$ further confirming the lack of an active chlorine chemistry cycle in the atmosphere of Mars.

\section{Conclusions}

The NOMAD ("Nadir and Occultation for MArs Discovery") spectrometer suite will be part of the ExoMars Trace Gas Orbiter 2016 mission. NOMAD will conduct a spectroscopic survey of Mars' atmosphere in UV, visible and IR wavelengths covering the $0.2-$ 0.65 and $2.3-4.3 \mu \mathrm{m}$ spectral ranges. The instrument is composed of 3 channels: a solar occultation only channel (SO) operating in the infrared wavelength domain, a second infrared channel capable of doing nadir, but also solar occultation and limb observations (LNO), and an ultraviolet/visible channel (UVIS) that can work in all observation modes. The spectral resolution of SO and LNO surpasses previous surveys in the infrared by more than one order of magnitude. Also the vertical resolution of the solar occultation channels exceeds that of previous composition mea-surements (Maltagliati et al., 2011) by a factor of $\sim 3$. NOMAD offers an integrated instrument combination of a flight-proven concept (SO is a copy of SOIR on Venus Express), and innovations based on existing and proven instrumentation (LNO is based on SOIR on board Venus Express and UVIS has heritage from the ExoMars lander), that will provide mapping and vertical profile information at high spatio-temporal resolution.

Compared to the numbers announced in the preliminary study (Drummond et al., 2011), the SNR levels derived from the optical models of the channels are higher for solar occultation, even if for the performances calculation we considered a lower conservative value. They are however reduced for nadir observations, due to the de-scope of the cryo-radiator which was present in the initial design to decrease the temperature in order to limit the thermal noise. Considering these updated SNR values, the methane detection level is ppt in solar occultation mode and $11 \mathrm{ppb}$ in nadir. These values are still lower than the abundances observed by previous experiments, and of the same order of magnitude in nadir as obtained by the Curiosity rover which detected levels of the order of $7 \mathrm{ppb}$ very recently at the surface in the Gale crater (Webster et al., 2015), and offer a significant improvement in occultation (Webster et al., 2015). In summary, NOMAD will provide a huge contribution to the ongoing investigations regarding detections of $\mathrm{CH}_{4}$ on Mars and will also deliver high-spatial resolution observations of many trace atmospheric species.

\subsection{The NOMAD team}

Vandaele, Ann Carine; Lopez Moreno, Jose Juan; Bellucci, Giancarlo; Patel, Manish; Allen, Mark; Altieri, Francesca; Aoki, Shohei; Bolsée, David; Clancy, Todd; Cloutis, Edward; Daerden, Frank; Depiesse, Cédric; Fedorova, Anna; Formisano, Vittorio; Funke, Bernd;, Fussen, Didier; Garcia-Comas, Maya; Geminale, Anna; Gérard, Jean-Claude; Gillotay, Didier; Giuranna, Marco; Gonzalez-Galindo, Francisco; Ignatiev, Nicolai; Kaminski, Jacek; Karatekin, Ozgur; Kasabe, Yasumasa; Lefèvre, Franck; Lewis, Stephen; López-Puertas, Manuel; López-Valverde, Miguel; Mahieux, Arnaud; Mason, Jon; Mumma, Mike; Neary, Lori; Neefs, Eddy; Renotte, Etienne; Robert, Séverine; Sindoni, Giuseppe; Smith, Mike; Thomas, Ian R.; Trokhimovsky, Sacha; Vander Auwera, Jean; Villanueva, Geronimo; Whiteway, Jim; Willame, Yannick; Wilquet, Valerie; Wolff, Mike - Tech Team: Alonso-Rodrigo, Gustavo; Aparicio del Moral, Beatriz; Barzin, Pascal; BenMoussa, Ali; Berkenbosch, Sophie; Biondi, David; Bonnewijn, Sabrina; Candini, Gian Paolo; Clairquin, Roland; Cubas, Javier; Delanoye, Sofie; 
Giordanengo, Boris; Gissot, Samuel; Gomez, Alejandro; Zafra Jose- Jeronimo; Leese, Mark; Maes, Jeroen; Mazy, Emmanuel; Mazzoli, Alexandra; Meseguer, Jose; Morales, Rafael; Orban, Anne; Pastor-Morales, Maria del Carmen; Perez-Grande, Isabel; Ristic, Bojan; Rodriguez-Gomez, Julio; Saggin, Bortolino; Samain, Valérie; Sanz Andres, Angel; Sanz, Rosario; Simar, Juan-Felipe; Thibert, Tanguy

\section{Acknowledgments}

The NOMAD instrument is led by the Belgian Institute for Space Aeronomy (BIRA-IASB, Brussels), assisted by Co-PI teams from Spain (IAA-CSIC, Granada), Italy (IAPS, Rome), and the United Kingdom (Open University, Milton-Keynes). Associated teams contributing to the design and development of NOMAD were CSL (Liège, Belgium) and IDR-UPM (Madrid, Spain). We thank all engineering and supporting personnel in these teams for their hard and solid work. Several industrial partners were also associated with the project: we would like to thank in particular the Belgian prime contractor (OIP, Oudenaarde) and the different subcontractors in Belgium and other partners' countries.

NOMAD has been made possible thanks to funding by the Belgian Science Policy Office (BELSPO) and financial and contractual coordination by the ESA Prodex Office (Grant number: PEA 4000107727). The research was performed as part of the "Interuniversity Attraction Poles" program financed by the Belgian government (Planet TOPERS). Spanish Institutions, IAA-CSIC and IDR-UPM were funded by Plan Nacional under Projects AYA201239691-C02-01 and 02. UK funding is acknowledged under the UK Space Agency grant ST/I003061/1.

\section{References}

Allen, M.A., Sherwood Lollar, B., Runnegar, B., Oehler, D.Z., Lyons, J.R., Manning, C.E., Summers, M.E., 2006. Is Mars alive? EOS: Trans. Am. Geophys. Union 87, 433-439.

Atreya, S., Mahaffy, P.R., Wong, A.-S., 2007. Methane and related trace species on Mars: origin, loss, implications for life, and habitability. Planet. Space Sci. 55, 358-369.

Atreya, S.K., Witasse, O., Chevrier, V., Forget, F., Mahaffy, P., Price, P., Webster, C., Zurek, R., 2011. Methane on Mars: current observations, interpretation, and future plans. Planet. Space Sci. 59, 133-136.

Bertaux, J.-L., Vandaele, A.C., Wilquet, V., Montmessin, F., Dahoo, R., Villard, E., Korablev, O., Fedorova, A., 2008. First observation of $628 \mathrm{CO}_{2}$ isotopologue band at $3.3 \mu \mathrm{m}$ in the atmosphere of Venus by solar occultation from Venus Express. Icarus 195, 28-33.

Bertaux, J.L., Montmessin, F., 2001. Isotopic fractionation through water vapor condensation: the deuteropause, a cold trap for deuterium in the atmosphere of Mars. J. Geophys. Res. 106, 32879-32883.

Bertaux, J.L. Nevejans, D. Korablev, O. Villard, E. Quémerais, E. Neefs, E. Montmessin, F., Leblanc, F., Dubois, J.P., Dimarellis, E., Hauchecorne, A., Lefevre, F., Rannou, P., Chaufray, J.Y., Cabane, M., Cernogora, G., Souchon, G., Semelina, F., Reberac, A., Van Ransbeek, E., Berkenbosch, S., Clairquin, R., Muller, C., Forget, F., Hourdin, F., Talagrand, O., Rodin, A., Fedorova, A., Stepanov, A., Vinogradov, A. Kiselev, A., Kalinnikov, Y., Durry, G., Sandel, B., Stern, A., Gérard, J.C., 2007. SPICAV on Venus Express: three spectrometers to study the global structure and composition of the Venus atmosphere. Planet. Space Sci. 55, 1673-1700.

Cantor, B., James, P.B., Caplinger, M., Wolff, M., 2001. Martian dust storms: 1999 Mars orbiter camera observations. J. Geophys. Res. 106, 23653-23687.

Cantor, B.A., 2007. MOC observations of the 2001 Mars planet-encircling dust storm. Icarus 186, 60-96.

Chassefière, E., 2009. Metastable methane clathrate particles as a source of methane to the Martian atmosphere. Icarus 204, 137-144

Cheng, B.M., Chew, E.P., Liu, C.P., Bahou, M., Lee, Y., Yung, Y.L., Gerstell, M., 1999. Photo-induced fractionation of water isotopomers in the martian atmosphere. Geophys. Res. Lett. 26, 3657-3660.

Clancy, R.T., Grossman, A.W., Wolff, M.J., James, P.B., Rudy, D.J., Billawala,

Y.N.Sandor, B.J., Lee, S.W., Muhleman, D.O., 1996. Water vapor saturation at low latitudes around aphelion: a key to Mars climate? Icarus 122, 36-62.

Clancy, R.T., Wolff, M.J., Whitney, B.A., Cantor, B.A., Smith, M.D., McConnochie, T.H. 2010. Extension of atmospheric dust loading to high altitudes during the 2001 Mars dust storm: MGS TES limb observations. Icarus 207, 98-109.
Daerden, F., Larsen, N., Chabrillat, S., Errera, Q., Bonjean, S., Fonteyn, D., Hoppel, K., Fromm, M., 2007. A 3D CTM with detailed online PSC-microphysics: analysis of the Antarctic winter 2003 by comparison with satellite observations. Atmos. Chem. Phys. 7, 1755-1772.

Daerden, F., Whiteway, J.A., Davy, R., Verhoeven, C., Komguem, L., Dickinson, C., Taylor, P.A., Larsen, N., 2010. Simulating observed boundary layer clouds

on Mars. Geophys. Res. Lett. 37, L04203.

Daerden, F., Whiteway, J.A., Neary, L., Komguem, L., Lemmon, M.T., Heavens, N.G., Cantor, B., Hébrard, E., Smith, M.D., 2015. A solar escalator on Mars: self-Lifting of dust layers by radiative heating. Geophys. Res. Lett. 42, 7319-7326.

Drummond, R., Vandaele, A.C., Daerden, F., Fussen, D., Mahieux, A., Neary, L., Neefs, E., Robert, S., Willame, Y., Wilquet, V., 2011. Studying methane and other trace species in the Mars atmosphere using a SOIR instrument. Planet. Space Sci. 59, 292-298.

Encrenaz, T., Greathouse, T., Richter, M., Lacy, J., Fouchet, T., Bézard, B., Lefèvre, F. Forget, F., Atreya, S., 2011. A stringent upper limit to $\mathrm{SO}_{2}$ in the

Martian atmosphere. Astron. Astrophys. 530, A37.

Errera, Q., Daerden, F., Chabrillat, S., Lambert, J.-C., Lahoz, W.A., Viscardy, S., Bonjean, S., Fonteyn, D., 2008. 4D-Var assimilation of MIPAS chemical observations: ozone and nitrogen dioxide anaylses. Atmos. Chem. Phys. 8, 6169-6187.

Fedorova, A., Korablev, O., Vandaele, A.C., Bertaux, J.-L., Belyaev, D., Mahieux, A. Neefs, E., Wilquet, V., Drummond, R., Montmessin, F., Villard, E., 2008. HDO and $\mathrm{H}_{2} \mathrm{O}$ vertical distribution and isotopic ratio in the Venus mesosphere by SOIR spectrometer on board Venus Express. J. Geophys. Res. 113. http://dx.doi.org/ 10.1029/2008JE003146.

Fonti, S., Marzo, G.A., 2010. Mapping the methane on Mars. Astron. Astrophys.

512, A51.

Formisano, V., Atreya, S., Encrenaz, T., Ignatiev, N., Giuranna, M., 2004. Detection of methane in the atmosphere of Mars. Science 306, 1758-1761.

Formisano, V., Angrilli, F., Arnold, G., Atreya, S.K., Bianchini, G., Biondi, D., Blanco,

A., Blecka, M.I., Coradini, A., Colangeli, L., Ekonomov, A.P., Esposito, F., Fonti, S. Giuranna, M., Grassi, D., Gnedykh, V., Grigoriev, A., Hansen, G., Hirsch, H. Khatuntsev, I., Kiselev, A., Ignatiev, N.I., Jurewicz, A., Lellouch, E., Lopez Moreno, J.J., Marten, A., Mattana, A., Maturilli, A., Mencarelli, E., Michalska, M., Moroz, V., Moshkin, B., Nespoli, F., Nikolsky, Y., Orfei, R., Orleanski, P., Orofino, V., Palomba, E., Patsaev, D., Piccioni, G., Rataj, M., Rodrigo, R., Rodriguez, J., Rossi, M., Saggin, B., Titov, D., Zasova, L.V., 2005. The Planetary Fourier Spectrometer (PFS) onboard the European Mars Express mission. Planet. Space Sci. 53, 963-974.

Geminale, A., Formisano, V., Giuranna, M., 2008. Methane in martian atmosphere: average spatial, diurnal and seasonal behaviour. Planet. Space Sci. 56, 1194-1203.

Geminale, A., Formisano, V., 2009. Planetary Fourier Spectrometer observation of $\mathrm{CO}_{2}(628)$ isotopologue on Mars. J. Geophys. Res. 114, E02004.

Geminale, A., Formisano, V., Sindoni, G., 2011. Mapping methane in Martian atmosphere with PFS-MEX data. Planet. Space Sci., 137-148.

Gierasch, P.J., Goody, R.M., 1972. The effect of dust on the temperature of the Mars atmosphere. J. Atmos. Sci. 29, 400-402.

Grotzinger, J.P., Crisp, J., Vasavada, A.R., Anderson, R.C., Baker, C.J., Barry, R., Blake,

D. F., Conrad, P., Edgett, K.S., Ferdowski, B., Gellert, R., Gilbert, J.B., Golombek, M., Gómez-Elvira, J., Hassler, D.M., Jandura, L., Litvak, M., Mahaffy, P., Maki, J., Meyer, M., Malin, M.C., Mitrofanov, I., Simmonds, J.J., Vaniman, D., Welch, R.V., Wiens, R.C., 2012. Mars science laboratory mission and science investigation. Space Sci. Rev. 170, 5-56.

Hartogh, P., Jarchow, C., Lellouch, E., De Val-Borro, M., Rengel, M., Moreno, R. Medvedev, A.S., Sagawa, H., Swinyard, B.M., Cavalié, T., Lis, D.C., Blecka, M.I. Banaszkiewicz, M., Bockelée-Morvan, D., Crovisier, J., Encrenaz, T., Küppers, M. Lara, L-M., Szutowicz, S., Vandenbussche, B., Bensch, F., Bergin, E.A, Billebaud, F., Biver, N., Blake, G.A., Blommaert, J.A.D.L., Cernicharo, J., Decin, L., Encrenaz, P., Feuchtgruber, H., Fulton, T., De Graauw, T., Jehin, E., Kidger, M., Lorente, R., Naylor, D.A., Portyankina, G., Sanchez-Portal, M., Schieder, R., Sidher, S., Thomas, N., Verdugo, E., Waelkens, C., Whyborn, N., Teyssier, D., Helmich, F. Roelfsema, P., Stutzki, J., LeDuc, H.G., Stern, J.A., 2010. Herschel/HIFI observations of Mars: first detection of $\mathrm{O}_{2}$ at submillimetre wavelengths and upper limits on $\mathrm{HCl}$ and $\mathrm{H}_{2} \mathrm{O}_{2}$. Astron. Astrophys. 521. http://dx.doi.org/10.1051/ 0004-6361/201015160.

Heavens, N.G., Cantor, B., Hayne, P., Kass, D., Kleinbohl, A., McCleese, D., Piqueux, S. Schofield, J.T. Shirley, J.H., 2015. Extreme detached dust layers near martian volcanoes: evidence for dust transport by mesoscale circulations forced by high topography. Geophys. Res. Lett. 42, 3730-3738. http://dx.doi.org/10.1002/ 2015GL064004

Hecht, M., Kounaves, S., Quinn, R., West, S., Young, S., Ming, D., Catling, D., Clark, B., Boynton, W.V., Hoffman, J., DeFlores, L., Gospodinova, K., Kapit, J., Smith, P.H., 2009. Detection of perchlorate and the soluble chemistry of martian soil at the phoenix lander site. Science 325, 64-67.

Hitchcock, D.R., Lovelock, J.E., 1967. Life detection by atmospheric analysis. Icarus 7, 149-159.

Khayat, A., Villanueva, G., Mumma, M., Tokunaga, A., 2015. A search for $\mathrm{SO}_{2}, \mathrm{H}_{2} \mathrm{~S}$

andSO above Tharsis and Syrtis volcanic districts on Mars using ground-based high-resolution submillimeter spectroscopy. Icarus 253, 130-141.

Knak-Jensen, S., Skibsted, J., Jakobsen, H., ten Kate, I., Gunnlauggson, H., Merrison, J., Finster, K., Bak, E., Iversen, J., Kondrup, J., Nornberg, P., 2014. A sink for methane on Mars? The answer is blowing in the wind. Icarus 236, 24-27.

Korablev, O., Ackerman, M., Krasnopolsky, V.A., Moroz, V.I., Muller, C., Rodin, A., Atreya, S.K., 1993. Tentative identification of formaldehyde in the Martian atmopshere. Planet. Space Sci. 41, 441-451. 
Korablev, O., 2002. Solar occultation measurements of the martian atmosphere on the phobos spacecraft: water vapor profile, aerosol parameters, and other results. Solar Syst. Res. 36, 12-34.

Krasnopolsky, V., Mumma, M.J., Gladstone, G.R., 1998. Detection of atomic deuterium in the upper atmosphere of Mars. Science 280, 1576-1580. Krasnopolsky,

V., 2006a. Some problems related to the origin of methane on Mars. Icarus 180, 356-367.

Krasnopolsky, V., 2010. Atmospheric chemistry on Venus, Earth and Mars: main features and comparison. Planet. Space Sci. 59, 952-964. http://dx.doi.org/ 10.1016/j.pss.2010.1002.1011

Krasnopolsky, V., 2012. Search for methane and upper limits to ethane and $\mathrm{SO}_{2}$ on Mars. Icarus 217, 144-152

Krasnopolsky, V., Lefèvre, F., 2013. Chemistry of the atmospheres of Mars, Venus, and Titan. In: Mackwell, S., Simon-Miller, A., Harder, J., Bullock, M. (Eds.), Comparative Climatology of Terrestrial Planets. University of Arizona Press, Tucson.

Krasnopolsky, V.A., 1997. High-resolution spectroscopy of Mars at 3.7 and 8 microm: a sensitive search for $\mathrm{H}_{2} \mathrm{O}_{2}, \mathrm{H}_{2} \mathrm{CO}, \mathrm{HCl}$, and $\mathrm{CH}_{4}$, and detection of HDO. J. Geophys. Res. 102, 6525-6534.

Krasnopolsky, V.A., Bjoraker, G.L., Mumma, M.J., Jennings, D.E., 1997.

Highesolution spectroscopy of Mars at 3.7 and 8 microm: a sensitive search for $\mathrm{H}_{2} \mathrm{O}_{2}, \mathrm{H}_{2} \mathrm{CO}, \mathrm{HCl}$, and $\mathrm{CH}_{4}$, and detection of HDO. J. Geophys. Res. 102, 6525-6534

Krasnopolsky, V.A., Maillard, J.P., Owen, T.C., 2004. Detection of methane in the Martian atmosphere: evidence for life? Icarus 172, 537-547.

Krasnopolsky, V.A., 2005. A sensitive search for $\mathrm{SO}_{2}$ in the martian atmosphere: implications for seepage and origin of methane. Icarus 178, 487-492.

Krasnopolsky, V.A., 2006b. Some problems related to the origin of methane on Mars. Icarus 180, 359-367.

Krasnopolsky, V.A., 2007. Comment on "Methane on Mars: a product of $\mathrm{H}_{2} \mathrm{O}$ photolysis in the presence of CO" by A. Bar-Nun and V. Dimitrov. Icarus 188 540-542.

Krasnopolsky, V.A., 2009. Seasonal variations of photochemical tracers at low and midldle latitudes on Mars: observations and models. Icarus 201, 564-569.

Langevin, Y., Poulet, F., Bibring, J.P., Gondet, B., 2005. Sulfates in the North polar region of Mars detected by OMEGA/Mars express. Science 307, 1584-1586.

Lefevre, F., Lebonnois, S., Montmessin, F., Forget, F., 2004. Three-dimensional modeling of ozone on Mars. J. Geophys. Res. 109. http://

dx.doi.org/10.1029/2004JE002268.

Lefevre, F., Bertaux, J.L., Clancy, R.T., Encrenaz, T., Fast, K., Forget, F., Lebonnois, S. Montmessin, F., Perrier, S., 2008. Heterogeneous chemistry in the atmosphere of Mars. Nature 454, 971-975.

Lefevre, F., Forget, F., 2009. Observed variations of methane on Mars unexplained by known atmospheric chemistry and physics. Nature 460, 720

Lewis, S.R., Read, P.L., Conrath, B.J., Pearl, J.C., Smith, M.D., 2007. Assimilation of thermal emission spectrometer atmospheric data during the Mars Global Surveyor aerobraking period. Icarus 192, 327.

Lodders, K., Fegley, B., 1997. An oxygen isotope model for the composition of Mars. Icarus $126,373-394$

Maguire, W.C., 1977. Martian isotopic ratios and upper limits for possible minor constituents as derived from Mariner 9 infrared spectrometer data. Icarus 32 85-97.

Mahaffy, P.M., Webster, C.R., Cabane, M., Conrad, P.C., Coll, P., Atreya, S.K., Arvey,

R., Barciniak, M., Benna, M., Bleacher, L., Brinckerhoff, W.B., Eigenbrode, J.L., Carignan, D., Cascia, M., Chalmers, R.A., Dworkin, J.P., Errigo, T., Everson, P. Franz, H., Farley, R., Feng, S., Frazier, G., Freissinet, C., Glavin, D.P., Harpold, D.N., Hawk, D., Holmes, V., Johnson, C.S., Jones, A., Jordan, P., Kellogg, J., Lewis, J., Lyness, E., Malespin, C.A., Martin, D.K., Mauren, J., McAdam, A.C., McLennan, D., Nolan, T.J., Noriega, M., Pavlov, A.A., Prats, B., Raaen, E., Sheinman, O., Sheppard, D., Smith, J., Stern, J.C., Tan, F., Trainer, M., Ming, D.W., Morris, R.V., Jones, J., Gundersen, C., Steele, A., Wray, J., Botta, O., Leshin, L.A., Owen, T., Battel, S., Jakosky, B.M., Manning, H., Squyres, S., Navarro-González, R., McKay, C.P., Raulin, F., Sternberg, R., Buch, A., Sorensen, P., Kline-Schoder, R., Coscia, D., Szopa, C., Teinturier, S., Baffes, C., Feldman, J., Flesch, G., Forouhar, S., Garcia, R., Keymeulen, D., Woodward, S., Block, B.P., Arnett, K., Miller, R. Edmonson, C., Gorevan, S., Mumm, E., 2012. The sample analysis at Mars investigation and instrument suite. Space Sci. Rev. 170, 401-478.

Mahieux, A. Berkenbosch, S. Clairquin, R., Fussen, D., Mateshvili, N., Neefs, E. Nevejans, D., Ristic, B., Vandaele, A.C., Wilquet, V., Belyaev, D., Fedorova, A. Korablev, O., Villard, E., Montmessin, F., Bertaux, J.L., 2008. In-flight performance and calibration of SPICAV/SOIR on-board Venus Express. Appl. Opt. 47, 2252-2265.

Mahieux, A., Wilquet, V., Drummond, R., Belyaev, D., Fedorova, A., Vandaele, A.C., 2009. A new method for determining the transfer function of an acousto optical tunable filter. Opt. Express 17, 2005-2014.

Mahieux, A., Vandaele, A.C., Drummond, R., Robert, S., Wilquet, V., Fedorova, A., Bertaux, J.L., 2010. Densities and temperatures in the Venus mesosphere and lower thermosphere SOIR onboard Venus Express: retrieval technique. J. Geophys. Res. 115. http://dx.doi.org/10.1029/2010JE003589.

Mahieux, A., Vandaele, A.C., Robert, S., Wilquet, V., Drummond, R., Montmessin, F., Bertaux, J.L., 2012. Densities and temperatures in the Venus mesosphere and lower thermosphere SOIR on board Venus Express: carbon dioxide measurements at the Venus terminator. J. Geophys. Res. 117, E07001. http://dx.doi.org/ 10.1029/2012JE004058.

Mahieux, A., Vandaele, A.C., Bougher, S.W., Drummond, R., Robert, S., Wilquet, V., Piccialli, A., Montmessin, F., Tellmann, S., Pätzold, M., Häusler, B., Bertaux, J.L., 2015a. Update of the Venus density and temperature profiles at high altitude measured by SOIR on board Venus Express. Planet. Space Sci. 113-114,309-320.

Mahieux, A., Vandaele, A.C., Robert, S., Wilquet, V., Drummond, R., Lopez-Valverde M.A., Lopez-Puertas, M., Funke, B., Bertaux, J.L., 2015b. Rotational temperatures of Venus upper atmosphere as measured by SOIR on board Venus Express. Planet. Space Sci. 113-114, 347-358.

Maltagliati, L., Montmessin, F., Fedorova, A., Korablev, O., Forget, F., Bertaux, J.L., 2011. Evidence of water vapor in excess of saturation in the atmosphere of Mars. Science 333, 1868-1871.

Mateshvili, N., Fussen, D., Vanhellemont, F., Bingen, C., Dodion, J., Daerden, F. Verhoeven, C., Depiesse, C., Muller, C., Montmessin, F., 2007. Martian cloud distribution detected by SPICAM UV channel in nadir mode. Geophys. Res. Abstr. 9, 01282

Mateshvili, N., Fussen, D., Vanhellemont, F., Bingen, C., Dekemper, E., Loodts, N. Tetard, C., 2009. Water ice clouds in the Martian atmosphere: two Martian years of SPICAM nadir UV measurements. Planet. Space Sci. 57, 1022-1031.

McElroy, M.B., Donahue, T.M., 1972. Stability of the Martian atmosphere.

Science $177,986-988$.

Mischna, M., Allen, M., Richardson, M.I., Newman, C., Toigo, A., 2011. Atmospheric modeling of Mars methane surface releases. Planet. Space Sci. 59, 227-237.

Montabone, L., Forget, F., Millour, E., Wilson, R.J., Lewis, S., Cantor, B., Kass, D., Kleinbohl, A., Lemmon, M., Smith, M., Wolff, M., 2015. Eight-year climatology of dust optical depth on Mars. Icarus 251, 65-95.

Montmessin, F., Lefèvre, F., 2013. Transport-driven formation of a polar ozone layer on Mars. Nat. Geosci. 6, 930-933.

Moudden, Y., McConnell, J.C., Beagley, S.R., López Valverde, M.A., López Puertas,

M., 2005. Meteorological results from the Global Mars Multiscale Model at the Viking 1 lander site. Adv. Space Res. 36, 2169-2175.

Mumma, M.J., Villanueva, G., Campbell, R., Lyke, J., Conrad, A., Encrenaz, T., Hartogh, P., Kauefl, U., Novak, R., Tokunaga, A., 2009a. Tracing the Origin of Methane an Water on Mars: Mapping Regions of Active Release at Ultra-high Spatial Resolution Using Keck and VLT Under AO Control, DPS, Puerto Rico.

Mumma, M.J., Villanueva, G.L., Novak, R.E., Hewagama, T., Bonev, B.P., DiSanti, M.A., Mandell, A.M., Smith, M.D., 2009b. Strong release of methane on Mars in Northern summer 2003. Science 323, 1041-1045.

Nakagawa, H., Kasaba, Y., Maezawa, H., Hashimoto, A., Sagawa, H., Murata, I., Okano, S., Aoki, S., Moribe, N., Mizuno, A., Momose, M., Ohnishi, T., Mizuno, N., Nagahama, T., 2009. Search of $\mathrm{SO}_{2}$ in the Martian atmosphere by ground-based submillimeter observation. Planet. Space Sci. 57, 2123-2127.

Neary, L., Daerden, F., Viscardy, S., 2014. Simulations of $\mathrm{O}_{2}\left(\mathrm{a}^{1} \Delta \mathrm{g}\right)$ with GEM-Mars, EPSC Abstracts vol. 9, EPSC2014-564.

Neefs, E., Vandaele, A.C., Drummond, R., Thomas, I., Berkenbosch, S., Clairquin, R. Delanoye, S., Ristic, B., Maes, J., Bonnewijn, S., Pieck, G., Equeter, E., Depiesse, C., Daerden, F., Van Ransbeeck, E., Nevejans, D., Rodriguez, J., Lopez-Moreno, J.-J., Sanz, R., Morales, R., Candini, G.P., Pastor, C., Aparicio del Moral, B., Jeronimo, J. M., Gomez, J., Perez, I., Navarro, F., Cubas, J., Alonso, G., Gomez, A., Thibert, T. Patel, M.R., Belucci, G., De Vos, L., Lesschaeve, S., Van Vooren, N., Moelans, W. Aballea, L., Glorieux, S., Baeke, A., Kendall, D., De Neef, J., Soenen, A., Puech, P.Y. Ward, J., Jamoye, J.F., Diez, D., Vicario, A., Jankowski, M., 2015. NOMAD spectrometer on the ExoMars trace gas orbiter mission: part 1-design, manufacturing and testing of the infrared channels. Appl. Opt. 54, 8494-8520.

Neukum, G., Jaumann, R., Hoffmann, H., Hauber, E., Head, J.W., Basilevsky, A., Ivanov, B., Werner, S.C., Van Gasselt, S., Murray, J.B., McCord, T.B., 2004. Recent and episodic volcanic and glacial activity on Mars revealed by the high resolution stereo camera. Nature 432, 971-979.

Nevejans, D., Neefs, E., Van Ransbeeck, E., Berkenbosch, S., Clairquin, R., De Vos, L., Moelans, W. Glorieux, S., Baeke, A., Korablev, O. Vinogradov, I, Kalinnikov, Y, Bach, B., Dubois, J.P., Villard, E., 2006. Compact high-resolution space-borne echelle grating spectrometer with AOTF based on order sorting for the infrared domain from 2.2 to 4.3 micrometer. Appl. Opt. 45, 5191-5206.

Onstott, T.C., McGown, D., Kessler, J., Sherwood Lollar, B., Lehmann, K., Clifford, S.M., 2006. Martian $\mathrm{CH}_{4}$ : sources, flux, and detection. Astrobiology 6, 377-395. Owen, T., Biemann, K., Rushnek, D.R., Biller, J.E., Howarth, D.W., Lafleur, A.L., 1977.

The composition of the atmosphere at the surface of Mars. J. Geophys. Res. 82, 4635-4639.

Parkinson, T.D., Hunten, D.M., 1972. Spectroscopy and aeronomy of $\mathrm{O}_{2}$ on Mars.

J. Atmos. Sci. 29, 1380-1390.

Patel, M.R., Vandaele, A.C., Neefs, E., Drummond, R., Thomas, I., Berkenbosch, S., Clairquin, R., Delanoye, S., Ristic, B., Maes, J., Bonnewijn, S., Pieck, G., Equeter, E. Depiesse, C., Daerden, F., Van Ransbeeck, E., Nevejans, D., Rodriguez, J., LopezMoreno, J.-J., Sanz, R., Morales, R., Candini, G.P., Pastor, C., Aparicio del Moral, B. Jeronimo, J.M., Gomez, J., Perez, I., Navarro, F., Cubas, J., Alonso, G., Gomez, A., Thibert, T., Belucci, G., De Vos, L., Lesschaeve, S., Van Vooren, N., Moelans, W. Aballea, L., Glorieux, S., Baeke, A., Kendall, D., De Neef, J., Soenen, A., Puech, P.Y. Ward, J., Jamoye, J.F., Diez, D., Vicario, A., Jankowski, M., NOMAD, 2015. An integrated suite of three high-resolution spectrometers for the infrared, visible and ultraviolet domain for ESA's ExoMars mission - design, manufacturing and testing of the ultraviolet UVIS channel. Appl. Opt. (in preparation)

Perrier, S., Bertaux, J.-L., Lefevre, F., Lebonnois, S., Korablev, O., Fedorova, A., Montmessin, F., 2006. Global distribution of total ozone on Mars from SPICAM/MEX UV measurements. J. Geophys. Res. 11. http://dx.doi.org/10.1029/ 2006JE002681.

Robbins, S., Di Achille, G., Hynek, B., 2011. The volcanic history of Mars: highresolution crater-based studies of the calderas of 20 volcanoes. Icarus 211, 1179-1203. 
Robert, S., Vandaele, A.C., Thomas, I., Willame, Y., Daerden, F., Delanoye, S., Depiesse, C., Drummond, R., Neefs, E., Neary, L., Ristic, B., Lopez-Moreno, J.J., Patel, M.R., Bellucci, G., NOMAD, 2015. Performances of the NOMAD/ExoMars instrument. Icarus (in preparation)

Sherwood Lollar, B., Lacrampe-Couloume, G., Slater, G.F., Ward, J., Moser, D.P., Gihring, T.M., Lin, L.-H., Onstott, T.C., 2006. Unravelling abiogenic and biogenic sources of methane in the Earth deep subsurface. Chemical Geology 226, 328-339.

Smith, M., Wolff, M.J., Clancy, R.T., Murchie, S.L., 2009a. Compact Reconnaissance Imaging Spectrometer observations of water vapor and carbon monoxide. J.

Geophys. Res. 114, E00D03.

Smith, M.D., 2004. Interannual variability in TES atmospheric observations of Mars during 1999-2003. Icarus 167, 148-165.

Smith, M.D., 2009. THEMIS observations of Mars aerosol optical depth from 20022008. Icarus 202, 444-452.

Smith, P.H., Tamppari, L., Arvidson, R.F., Bass, D., Blaney, D., Boynton, W., Carswell, A.I., Catling, D.C., Clark, B., Duck, T., DeJong, E., Fisher, D., Goetz, W., Gunnlauggson, H., Hecht, M., Hipkin, V., Hoffman, J., Hviid, S.F., Keller, H.U., Kounaves, S., Lange, C., Lemmon, M., Madsen, M., Malin, M.C., Markiewicz, W., Marshall, B. T., McKay, C.P., Mellon, M., Michelangeli, D., Ming, D., Morris, R.V., Renno, N., Pike, W., Staufer, U., Stoker, C., Taylor, P.A., Whiteway, J.A., Young, S., Zent, A., 2009b. $\mathrm{H}_{2} \mathrm{O}$ at the Phoenix Landing Site. Science 325, 58-61.

Steele, L., Lewis, S., Patel, M., Montmessin, F., Forget, F., Smith, M.D., 2014. The seasonal cycle of water vapour on Mars from assimilation of Thermal Emission Spectrometer data. Icarus 237, 97-115.

Stern, J.C., Sutter, B., Freissinet, C., Navarro-González, R., McKay, C., Archer, D., Buch, A., Brunner, A., Coll, P., Eigenbrode, J., Fairen, A., Franz, H., Glavin, D., Kashyap, S., McAdam, A., Ming, D., Steele, A., Szopa, C., Wray, J.J., Martin-Torres, F.J., Zorzano, M.-P., Conrad, P., Mahaffy, P., 2015. Evidence for indigenous nitrogen in sedi-mentary and aeolian deposits from the Curiosity rover investigations at Gale crater, Mars. PNAS 112, 4245-4250.

Svedhem, H., Titov, D., McCoy, D., Lebreton, J.-P., Barabash, S., Bertaux, J.L., Drossart, P., Formisano, V., Häusler, B., Korablev, O., Markiewicz, W.J., Nevejans, D., Pätzold, M., Piccioni, G., Zhang, T.L., Taylor, F.W., Lellouch, E., Koschny, D., Witasse, O., Eggel, H., Warhaut, M., Accomazzo, A., Rodriguez-Canabal, J., Fabrega, J., Shirmann, T., Clochet, A., Coradini, M., 2007. Venus express: the first European mission to Venus. Planet. Space Sci. 55, 1636-1652.

Thomas I., Vandaele A.C., Robert S., Daerden F., Delanoye S., Depiesse C., Drummond R., Neefs E., Neary L., Ristic B., Willame Y., Lesschaeve S., Antoine P., LopezMoreno J.J., Patel M.R. and Bellucci G., Optical and radiometric models and performances of the NOMAD - instrument - Part II: the IR channels, SO and LNO, Opt. Express, 2015, (in preparation).

Titov, D.V., Svedhem, H., McCoy, D., Lebreton, J.P., Barabash, S., Bertaux, J.L., Drossart, P., Formisano, V., Haeusler, B., Korablev, O.I., Markiewicz, W., Neveance, D., Petzold, M., Piccioni, G., Zhang, T.L., Taylor, F.W., Lellouch, E., Koschny, D., Witasse, O., Warhaut, M., Accomazzo, A., Rodrigues-Cannabal, J., Fabrega, J., Schirmann, T., Clochet, A., Coradini, M., 2006. Venus express: scientific goals, instrumentation and scenario of the mission. Cosm. Res. 44, 334-348.

Trokhimovsky, A., Korablev, O., Grigoriev, A., Fedorova, A., Shakun, A., Ignatiev, N., Zasova, L.V., Moshkin, B., Dziuban, I., Guslyakova, S., Anufreychik, K., Stepanov, A., Titov, A., Montmessin, F., Ivanov, Y., Kalinnikov, Y., 2014. Atmospheric Chemistry Suite (ACS): a set of Infrared Spectrometers for Atmospheric Mea-surements on Board ExoMars Trace Gas Orbiter $15 \mathrm{mn}$. In: Proceedings of the Fifth international workshop on the Mars atmosphere: Modelling and obser-vations, Oxford, UK, January 13-16, 2014.

Vandaele, A.C., De Mazière, M., Drummond, R., Mahieux, A., Neefs, E., Wilquet, V. Korablev, O., Fedorova, A., Belyaev, D., Montmessin, F., Bertaux, J.L., 2008. Composition of the Venus mesosphere measured by SOIR on board Venus Express. J. Geophys. Res. 113, E00B23. http://dx.doi.org/10.1029/2008JE003140.

Vandaele, A.C., Mahieux, A., Robert, S., Berkenbosch, S., Clairquin, R., Drummond, R. Letocart, V., Neefs, E., Ristic, B., Wilquet, V., Colomer, F., Belyaev, D., Bertaux, J.L., 2013. Improved calibration of SOIR/Venus Express Spectra. Opt. Express 21, 21148.

Vandaele, A.C., Willame, Y., Depiesse, C., Thomas, I., Robert, S., Daerden, F., Delanoye, S., Drummond, R., Neefs, E., Ristic, B., Patel, M.R., Lesschaeve, S., Antoine, P., Lopez-Moreno, J.J., Bellucci, G., 2015. Optical and radiometric models and performances of the NOMAD instrument - Part I: the UVIS channel. Opt. Express (submitted for publication).

Villanueva, G., Mumma, M., Novak, R., Hewagama, T., Bonev, B.P., DiSanti, M., 2008a. Mapping the D/H of Water on Mars Using High-Resolution Spectroscopy, The Mars Atmosphere: Modeling and Observations. Williamsburg, Virginia, USA, Nov. 10-13.
Villanueva, G., Mumma, M.J., Novak, R., Hewagama, T., 2008b. Identification of a new band system of isotopic $\mathrm{CO}_{2}$ near $3.3 \mu \mathrm{m}$ : implications for remote sensing of biomarker gases on Mars. Icarus 195, 34-44.

Villanueva, G., Mumma, M.J., Novak, R., Hewagama, T., 2008c. Discovery of multiple bands of isotopic $\mathrm{CO}_{2}$ in the prime spectral regions used when searching for $\mathrm{CH}_{4}$ and $\mathrm{HDO}$ on Mars. J. Quant. Spectrosc. Radiat. Transf. 109, 883-894.

Villanueva, G., Mumma, M., Novak, R., Käufl, H.U., Hartogh, P., Encrenaz, P., Tokunaga, A., Khayat, A., Smith, M.D., 2015. Strong water isotopic anomalies in the martian atmosphere: probing current and ancient reservoirs. Science 348, 218-221.

Villanueva, G.L., Mumma, M.J., Novak, R.E., Radeva, Y.L., Käufl, H.U., Smette, A., Tokunaga, A., Khayat, A., Encrenaz, T., Hartogh, P., 2013. A sensitive search for organics $\left(\mathrm{CH}_{4}, \mathrm{CH}_{3} \mathrm{OH}, \mathrm{H}_{2} \mathrm{CO}, \mathrm{C}_{2} \mathrm{H}_{6}, \mathrm{C}_{2} \mathrm{H}_{2}, \mathrm{C}_{2} \mathrm{H}_{4}\right)$, hydroperoxyl $\left(\mathrm{HO}_{2}\right)$, nitrogen compounds $\left(\mathrm{N}_{2} \mathrm{O}, \mathrm{NH}_{3}, \mathrm{HCN}\right)$ and chlorine species $\left(\mathrm{HCl}, \mathrm{CH}_{3} \mathrm{Cl}\right)$ on Mars using ground-based high-resolution infrared spectroscopy. Icarus 223, 11-27.

Viscardy, S., Daerden, F., Neary, L., Garcia Munoz, A., Vandaele, A.C., 2015. Vandaele

Surface Release of Methane into the Atmosphere of Mars: A New Model Study, EGU, Geophysical Research Abstracts, Vienne, Austria, vol. 17, EGU2015-13053. Webster C., Mahaffy, P., Atreya, S.K., Flesch, G., Farley, K., 2013. Low upper limit to methane abundance on Mars. Science 342, 355-357.

Webster, C., Mahaffy, P., Atreya, S.K., Flesch, G., Mischna, M., Meslin, P.-Y., Farley, K., Conrad, P., Christensen, L., Pavlov, A., Martín-Torres, J., Zorzano, M., McConno-chie, T., Owen, T., Eigenbrode, J., Glavin, D., Steele, A., Malespin, C., Archer, P., Sutter, B., Coll, P., Freissinet, C., McKay, C., Moores, J., Schwenzer, S., Bridges, J., Navarro-González, R., Gellert, R., Lemmon, M., 2015. Mars methane detection and variability at gale crater. Science 347, 415-417.

Wennberg P., Hipkin, V.J., Drummond, J.R., Toon, G.C., Allen, M., Blavier, J.F., Brown, L.R., Kleinbohl, A., Abbatt, J., Sherwood Lollar, B., Strong, K., Walker, K.A., Bernath, P.F., Clancy, R.T., Cloutis, E.A., Des Marais, D.J., Eiler, J.M., Yung, Y., Encre-naz, T., McConnell, J.C., 2011. The Mars Atmospheric Trace Molecule Occultation Spectrometer. In: Proceedings of the 4th international workshop on the Mars atmosphere: Modelling and observations, Paris, France.

Whiteway, J.A., Komguem, L., Dickinson, C., Cook, C., Illnicki, M., Seabrook, J., Popovici, V., Duck, T.J., Davy, R., Taylor, P.A., Pathak, J., Fisher, D., Carswell, A.I. Daly, M., Hipkin, V., Tamppari, L., Renno, N., Moores, J., Lemmon, M., Daerden, F., Smith, H., 2009. Mars water ice clouds and precipitation. Science 325, 68-70.

Wilquet, V., Mahieux, A., Vandaele, A.C., Perevalov, V.I., Tashkun, S.A., Fedorova, A. Korablev, O., Montmessin, F., Dahoo, R., Bertaux, J.-L., 2008. Line parameters for the 01111-00001 band of ${ }^{12} \mathrm{C}^{16} \mathrm{O}^{18} \mathrm{O}$ from SOIR measurements of the Venus atmosphere. J. Quant. Spectrosc. Radiat. Transf. 109, 895-905.

Wilquet, V., Fedorova, A., Montmessin, F., Drummond, R., Mahieux, A., Vandaele, A C., Villard, E., Korablev, O., Bertaux, J.L., 2009. Preliminary characterization of the upper haze by SPICAV/SOIR solar occultation in UV to mid-IR onboard Venus Express. J. Geophys. Res. 114. http://dx.doi.org/10.1029/2008JE003186.

Wilquet, V., Drummond, R., Mahieux, A., Robert, S., Vandaele, A.C., Bertaux, J.L., 2012. Optical extinction due to aerosols in the upper haze of Venus: four years of SOIR/VEX observations from 2006 to 2010. Icarus 217, 875-881.

Wilson, R.J., Lewis, S., Montabone, L., Smith, M.D., 2008. Influence of water ice clouds on Martian tropical atmospheric temperatures. Geophys. Res. Lett. 35. http://dx.doi.org/10.1029/2007GL032405

Wolff, M.J., Clancy, R.T., Goguen, J.D., Malin, M.C., Cantor, B.A., 2010. Ultraviolet dust aerosol properties as observed by MARCI. Icarus 208, 143-155.

Wong, A.-S., Atreya, S.K., Encrenaz, T., 2003. Chemical markers of possible hot spots on Mars. J. Geophys. Res. 108. http://dx.doi.org/10.1029/2002JE002003.

Wong, A.S., Atreya, S.K., Encrenaz, T., 2004a. Correction to "Chemical markers

of possible hot spots on Mars". J. Geophys. Res. 108. http:// dx.doi.org/10.1029/2003JE002210.

Wong, A.S., Atreya, S.K., Formisano, V., Encrenaz, T., Ignatiev, N.I., 2004b. Atmospheric photochemistry above possible martian hot spots. Adv. Space Res. 33 , 2236-2239.

Wong, A.S., Atreya, S.K., Encrenaz, T., 2005. Correction to and updated reaction in "Chemical markers of possible hot spots on Mars". J. Geophys. Res. 110 http: //dx.doi.org/10.1029/2005JE002509.

Yung, Y., Russel, M.J., Parkinson, C., 2010. The search for life on Mars. J. Cosmol. 5, 1121-1130.

Zahnle, K., Freedman, R.S., Catling, D.C., 2011. Is there methane on Mars? Icarus 212, 493-503.

Zurek, R.W., Chicarro, A., Allen, M.A., Bertaux, J.L., Clancy, R.T., Daerden, F.,

For-misano, V., Garvin, J., Neukum, G., Smith, M.A., 2011. Assessment of a 2016 mission concept: the search for trace gases in the atmosphere of Mars. Planet. Space Sci. 59, 284-291. 